\title{
CHRONOLOGY AND PETROLOGY OF SILICATES FROM IIE IRON METEORITES: EVIDENCE OF A COMPLEX PARENT BODY EVOLUTION
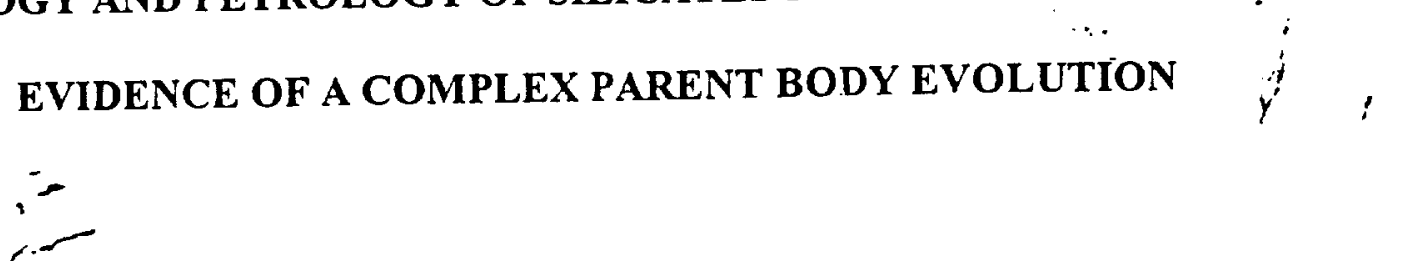

Donald D. Bogard ${ }^{1}$, Daniel H. Garrison ${ }^{2}$ and Timothy J. McCoy ${ }^{1,3}$

'Planetary Sciences, SN2, NASA/Johnson Space Center, Houston, TX 77058

${ }^{2}$ Lockheed-Martin Engineering and Johnson Space Center, Houston, TX 77058

${ }^{3}$ Dept. of Mineral Sciences, National Museum of Natural History,

Smithsonian Institution, Washington, DC 20560-0119

Submitted to Geochim. Cosmochim. Acta, 8/3/99 


\begin{abstract}
IIE iron meteorites contain silicate inclusions whose characteristics suggest a parent body similar to that of $\mathrm{H}$-chondrites. However, these silicates show a wide range of alteration, ranging from Netschaëvo and Techado, whose inclusions are little altered, to highly differentiated silicates like those in " Kojaikanal, Weekeroo Station and Colomera, which have lost metal and sulfur and are enriched in , feldspar. We findthese inclusions to show varying degrees of shock alteration. Because only a limited amount of data on isotopic ages of IIE silicates were available, we made ${ }^{39} \mathrm{Ar}-{ }^{40} \mathrm{Ar}$ age determinations of Watson, Techado, Miles, Colomera, and Sombrerete. Watson has an Ar-Ar age of $3.653 \pm 0.012 \mathrm{Gyr}$, similar to previously reported ages for Kodaikanal and Netschaëvo. We suggest that the various determined radiometric ages of these three meteorites were probably reset by a common impact event. The space exposure ages for these three meteorites are also similar to each other and are considerably younger than exposure ages of other IIEs. ${ }^{39} \mathrm{Ar}-{ }^{40} \mathrm{Ar}$ ages inferred for the other four meteorites analyzed are considerably older than Watson and are: Techado $=4.49 \pm 0.01 \mathrm{Gyr}$, Miles $=4.412 \pm 0.016 \mathrm{Gyr}$, Colomera $=4.469 \pm 0.012 \mathrm{Gyr}$, and Sombrerete $=4.535 \pm 0.005 \mathrm{Gyr}$. These ages are in fair agreement with previously reported Rb-Sr isochron ages for Colomera and Weekeroo Station. Although several mechanisms to form IIE meteorites previously were suggested, it is not obvious that a single mechanism could produce a suite of meteorites with very different degrees of silicate differentiation and with isotopic ages that differ by $>0.8 \mathrm{Gyr}$. We suggest that those IIEs with older isotopic ages are a product of partial melting and differentiation within the parent body, followed by mixing of silicate and metal while both were relatively hot. Netschaëvo and Watson may have formed by this same process or by impact mixing $\sim 4.5 \mathrm{Gyr}$ ago, but their isotopic ages were subsequently reset by shock heating. Kodiaikanal apparently is required to have formed more recently, in which case impact melting and differentiation seems the only viable process. We see no compelling reasons to believe that IIE silicate and metal derived from different parent bodies or that the parent body of IIEs was the same as that of Hchondrites.
\end{abstract}




\section{INTRODUCTION}

The diversity among meteorites reveais that some asteroidal parent bodies apparently never were heated sufficiently to cause significant melting and differentiation (e.g., the chondrites), whereas other parent bodies were appreciably meited and differentiated to the point that surface basalt flows (e.g., eucrites) and metal cores (e.g., some :ron meteorites) were formed. Still other meteorites suggést parént bodies where the degree of melting and differentiation fell in between these two extremes. On these bodies sufficient melting occurred $\leqslant 0$ as to produce separation of silicate and metal and even some differentiation of silicate, but surface basalt flows and metal cores may not have been produced. Examples of these types of meteontes are the acapulcoites-lodranites and the winonaites-IAB irons, where each pair is thought to represent a single parent body. Acapulcoites-lodranites represent originally chondritic-like material heated sufĩi:iently to differentiate and lose metal, and in the case of lodranites, also to lose a feldspar-rich, low meiting differentiate (Mittlefehldt et al., 1996; McCoy et al., 1997). Winonaites also are thought to have been derived from chondritic-like material by removal of metal (Benedix et al., 1998). In contrast. $L+B$ irons are mostly metal, but are thought to derive from the same parent as winonaites.

The IIE irons are another group of silicate-bearing iron meteorites. They define coherent trends on element-element plots of $\mathrm{Ni}$ vs. Ga. Ge, Co, Cu, As, Au, W and Ir (Wasson and Wang, 1986). Some of these trends can be readily explained by fractional crystallization of a large metallic body and might form during crystallization of a single core. Other element- trends in IIEs are not easily explained by such a mechanism and are more simitar to those in IAB irons. Wasson and Wang (1986) argue that these trends reflect formation of the metailic host by impact melting of the near-surface layer of an asteroid. The IIE irons also display a wide range of silicate inclusion types, from angular, chondrule-bearing inclusions, to small globular, strongly differentiated, feldspar-rich inclusions. An unusual characteristic of IIE meteorites is that some show relatively old isotopic formation ages of $-4.5 \mathrm{Gyr}$, whereas a few indicate ages that are younger by $\sim 0.8 \mathrm{Gyr}$ (Burnett and Wasserburg, 1967a; Niemeyer, 1979; Olsen et al., 1994). Ages significantly younger than $\sim 4.5 \mathrm{Gyr}$ are seen in some other meteorite types and are commonly ascribed to resetting by large impact events (Bogard, 1995). By analogy to the IAB irons (which all have ages of $\sim 4.5 \mathrm{Gyr}$, as far as is known) we might surmise that the IIE metal-silicate assemblage formed by igneous processes within the parent body. On the other hand the young isotopic ages might imply formation by impact mixing at much later time. Previous workers have invoked both internal parent body metamorphism and impact meiting to explain the formation of differentiated silicates and metal-silicate mixing $\mathrm{n}$ the IIE irons (Mittlefehldt et al., 1998 and reference therein). 
Only a limited amount of isotopic chronology data has been available for IIE meteorites. Thus, we initiated an investigation to determine the ${ }^{39} \mathrm{Ar}-{ }^{40} \mathrm{Ar}$ ages of silicate from four IIE meteorites (Watson, Techado. Miles, Colomera) and the ungrouped but closely-related silicate-bearing iron Sombrerete. When we began our study, no precise isotopic ages existed for four of these meteorites. The ${ }^{39} \mathrm{Ar}-{ }^{40} \mathrm{Ar}$ technique is particularly sensitive to resetting by only moderate heating events. In addition, we ' measured noble gases in four of these meteorites to better estimate space exposure ages. We also made additional petrological studies of silicate in several IIE meteorites, with particular emphasis on shock features.

\section{SAMPLES AND TECHNIQUES}

Eight silicate-bearing iron meteorites have been classified as IIE or IIE-An on the basis of their metal compositions: Weekeroo Station, Colomera, Elga, Netschaëvo, Kodaikanal, Techado, Miles and Watson (Wasson et al., 1986; Olsen et al., 1994). These meteorites also share a common oxygen isotopic signature, with $\Delta^{17} \mathrm{O}$ of $0.59 \pm 0.07$ for all 8 (Clayton and Mayeda, 1996). Several other meteorites, which are ungrouped on the basis of their metal composition or for which the metal composition is unknown, have also been suggested to have close ties to group IIE. These include Guin (Rubin et al., 1985), Sombrerete (Prinz et al., 1983), Yamato 791093 (Ikeda et al., 1997a) and Portales Valley (Rubin and Ulff-Moller, 1999). Sombrerete contains globular silicate inclusions and is similar to IIEs in many respects. Its inclusions consist of orthopyroxene, phosphate, plagioclase, $\mathrm{SiO}_{2}$ and feldspathic glass, similar to inclusions in Weekeroo Station and Miles. However, Malvin et al. (1984) found that the Ge concentration of the metallic host and oxygen isotopic composition of Sombrerete silicate preclude grouping Sombrerete with the IIE irons. It seems most likely that Sombrerete formed in a manner analogous to those "old" IIE's with globular inclusions, but on a separate parent body.

For this petrologic study, we focused on the main group IIE irons, conducting examinations of Miles (UH 261), Techado (UNM 1054), Weekeroo Station (USNM 835), Netschaëvo (USNM 494-3, 1096), Colomera (USNM 3396-4), Kodaikanal (USNM 2858) and Watson (UH 260). No sample of Elga was available for our study. We briefly examined PTS ,51-2 of Yamato 791093 at the National Institute of Polar Research. Polished thin section and polished sections of meteorites were examined in transmitted and reflected light. Imaging, qualitative and quantitative analyses of selected phases in silicate-bearing IIE irons, was conducted using the SX-100 electron microprobe at Johnson Space Center, Houston, Texas. Modal analyses of 400-1500 point was conducted on Techado and Miles.

We neutron irradiated silicate samples of Watson, Miles, Techado, Colomera (feldspar), and Sombrerete (USNM 5870) for ${ }^{39} \mathrm{Ar}-{ }^{40} \mathrm{Ar}$ analysis. The Miles sample was from the same silicate clast for 
which the petrographic description was made. The Watson sampie was received from J. Schwade and is from the same large silicate inclusion studied by Olsen et al. (1994). The Colomera feldspar separate was received from J. Wasserburg and is the same material studied by Wasserburg et al. (1968) and Sanz et al. (1970). The Techado sample analyzed was received courtesy of A. Brearly (Iristitute of : Meteoritics) and was taken from the same silicate clast for which the petrographic description was mate. It consisted of several small pieces of intergrown silicate, metal, and metal oxide from which we were able to extract only $10 \mathrm{mg}$ of silicate for Ar-Ar analysis. This Techado sample is not the same inclusion studied by Casanova et al. (1995). The Sombrerete sample received was mostly metal with thin, beadlike strings of silicate. The metal was dissolved in cold, $1 \mathrm{~N}$ nitric acid for three days. This process left several white and gray inclusions a few $\mathrm{mm}$ in diameter. A single white inclusion weighing $13 \mathrm{mg}$ was used for Ar-Ar dating and a separate inclusion for cosmogenic studies.

The five meteorite samples Ar-Ar dated, along with samples of the NL-25 hornblende age monitor, were irradiated in four separate neutron irradiations. Argon was released by stepwise degassing in a high vacuum furnace and its isotopic composition was measured on a Nuclide mass spectrometer. Argon isotopic data are given in Appendix 1. We also analyzed noble gas concentrations in uniradiated silicate samples of Netschaëvo (USNM 2957), Miles, Sombrerete, and Colomera (feldspar) for the purpose of comparing space exposure ages. Noble gases were released from these samples in two temperature steps and analyzed on a VG-3600 mass spectrometer that has not been exposed to irradiated samples. Additional details of the techniques are given in Garrison et al. (1992) and Garrison and Bogard (1998).

\section{RESULTS}

\section{Petrography}

In this section, we briefly review the mineralogy, modes, and mineral chemistry of the diverse array of silicate inclusions found in IIE iron meteorites, primarily summarizing the work of others. We report new observations on shock features within the IIE irons.

"Chondritic" Inclusions: A number of IIE irons have inclusions which are either chondrulebearing or roughly chondritic in their mineralogy and mineral abundances. We have studied "chondritic" inclusions in Techado, Netschaevo and Watson. Chondrule-bearing inclusions also are found in Yamato 791093 (Ikeda et al., 1997a) and Portales Valley (Rubin and Ulff-Moller, 1999), but these meteorites were not included in our study.

Netschaëvo contains angular clasts $1.2 \mathrm{~cm}$ in length (Fig. 1a) which include recrystallized chondrules typical of those found in type 6 ordinary chondrites (Bunch et al., 1970; Olsen and Jarosewich, 1971; Bild and Wasson, 1977). The silicate mineralogy of these clasts is essentially 
Identical to chondrites (Table 1), containing olivine $\left(\mathrm{Fa}_{141}\right)$, orthopyroxene $\left(\mathrm{Fs}_{13.6}\right)$, plagioclase and phosphates. although the clasts are richer in orthopyroxene and phosphates, poorer in olivine, and contain mafic silicates more reduced than found in $\mathrm{H}$ chondrites. Olivine in the silicate inclusions exhibits undulatory extinction, healed fractures decorated with opaques or, more commonly, yoids, and rare planar fractures. Compound Fe,Ni-FeS-oxide particles exhibit eutectic intergrowths and kamatite has been converted tơthe $\alpha_{2}$ structure (Buchwald, 1975). The features within olivine would suggest classification as shock stage S2-S3 (Stöffler et al., 1991) and post-shock temperature increase of 50$100^{\circ} \mathrm{C}$. However, Netschaëvo was forged shortly after its recovery and locally reheated to temperatures above $1000^{\circ} \mathrm{C}$ (Buchwald, 1975). The effect reheating to this temperature may have on annealing of shock features is not known.

Casanova et al. (1995) described a single silicate inclusion $\sim 1.5 \mathrm{~cm}$ in length from Techado (Fig. lb). This inclusion is roughly chondritic in bulk mineralogy (Table 1 ), consisting of olivine $\left(\mathrm{Fa}_{16,4}\right)$, orthopyroxene $\left(\mathrm{Fs}_{15.3}\right)$, plagioclase $\left(\mathrm{An}_{1,2,15.4} \mathrm{Or}_{5,5-6.3}\right), \mathrm{Fe}, \mathrm{Ni}$ metal and troilite. Although Casanova et al. (1995) suggested that the inclusion was unmelted, it has an unusual elongated shape that suggests that it was heated to temperatures sufficient to cause the inclusion to soften and become stretched. Casanova et al. (1995) suggested that the inclusion was unshocked. Our examination suggests that olivine and orthopyroxene both exhibit planar fractures and undulatory extinction, suggesting classification as S3 (Stöffler et al., 1991) and post-shock heating of $100-150^{\circ} \mathrm{C}$. Neumann bands are also present in the metallic host of Techado.

Olsen et al. (1994) reported a comprehensive study of Watson, including the discovery of a single silicate inclusion of $-30 \mathrm{~cm}^{3}$ (Fig. 1c). The Watson inclusion is roughly chondritic in bulk composition (Olsen et al., 1994). A calculated modal mineralogy of this inclusion (Olsen et al., 1994; Table 1) contains $57 \%$ olivine $\left(\mathrm{Fa}_{20.6}\right), 23 \%$ orthopyroxene $\left(\mathrm{Fs}_{17.6} \mathrm{Wo}_{3.8}\right)$ and $12 \%$ feldspar; Fe,Ni metal and troilite are essentially absent. The texture is decidedly non-chondritic and similar to that of a terrestrial peridotite (Olsen et al., 1994). The silicate inclusion is dominated by orthopyroxene crystals of 0.5-2 $\mathrm{mm}$ in maximum dimension, which poikilitically enclose olivine crystals. Olsen et al. (1994) noted the presence of dendritic melt pockets, $\alpha_{2}$ structure, and Neumann bands within the metallic host. The first two of these suggest brief, local heating to temperatures in excess of $700^{\circ} \mathrm{C}$. We have observed a number of other features related to post-formational shock, including shearing of the large inclusion and undulatory extinction and planar fractures in both olivine and pyroxene. These features correspond to shock stage $S 3$ and post-shock heating of $100-150^{\circ} \mathrm{C}$

Differentiated Inclusions: The remaining silicate-bearing IIE irons (Weekeroo Station, Miles, Colomera, Kodaikanal and Elga) all contain what Prinz et al. (1983) aptly described as globular silicate 
inclusions. These inclusions are typically rounded to elongate, can reach $1 \mathrm{~cm}$ in length and typically comprise -10 vol. \% of the bulk meteonte (Fig. 1d). Inclusions in Weekeroo Station and Miles are dominantly orthopyroxene, clinopyroxene and plagioclase in a ratio of $1: 1: 2$, while Colomera, Kodaikanal and Elga inclusions contain major clinopyroxene and plagioclase $(-1: 2$ or $-1: 3)$ with only minor orthopyroxene (Table 1). These inclusion have been studied by Bunch and Olsen (1968), ; Wasserburg et al. (1968), Bence and Burnett (1969), Bunch et al. (1970), Olsen and Jarosewich (1970), Osadchii et al. (1981), Prinz et al. (1983), and Ikeda and Prinz (1996). Silicate inclusions in the ungrouped irons Guin (Rubin et al., 1985) and Sombrerete (Prinz et al., 1982) are similar to the differentiated inclusions in group IIE irons.

Weekeroo Station, Miles, Colomera, Kodaikanal and Elga contain (1) coarse-grained (up to $5 \mathrm{~mm}$ grain size) gabbroic inclusions (Fig. 2a), (2) partially- to wholly-cryptocrystalline inclusions (Fig. 2b) and (3) glassy inclusions (Fig. 2c). The ratio of these types can differ significantly. In Miles, most inclusions are gabbroic (Ikeda and Prinz, 1996; Ikeda et al., 1997b), while most inclusions in Weekeroo Station and Elga are at least partially-cryptocrystalline. Glassy inclusions are found in Colomera and Kodaikanal. Gabbroic inclusions in Miles consist of 1-5 mm grains of feldspar (both plagioclase and potassium feldspar), augite $\left(\mathrm{Fs}_{8-12} \mathrm{Wo}_{40-15}\right)$, and orthopyroxene ( $\mathrm{Fs}_{19-23}$; Ikeda and Prinz, 1996; this work). Millimeter-sized chromite grains are also found in the gabbroic inclusions. Grain boundaries are irregular and often interfinger. Cryptocrystalline inclusions are typified by the corona structure found in Weekeroo Station (Bunch et al., 1970) with a large (up to several $\mathrm{mm}$ ) corroded augite $\left(\mathrm{Fs}_{17.6}\right)$ rimmed by orthopyroxene ( $\mathrm{Fs}_{22.2}$; Bunch et al., 1970) and surrounded by a fine-grained radiating structure of acicular feldspar. tridymite and glass. Ikeda et al. (1997b) illustrated an almost identical structure in Miles. Colomera contains these two types of inclusions, as well as glassy inclusions (Buchwald, 1975). In some areas, we have observed that all three types of inclusions can be found co-existing in an area of $\sim 1 \mathrm{~cm}^{2}$, well below the heat-altered zone of the meteorite. The glasses tend to be feldspathic in nature (this work) and often contain immiscible phosphate-rich melts (Buchwald, 1975).

Shock features are abundant within IIE irons with differentiated silicate inclusions. Buchwald (1975) reported violently deformed Neumann bands, fractured schreibersite and shock-melted troilite in the vicinity of silicate inclusions in Colomera and fracturing of schreibersite and dispersion of troilite in Weekeroo Station. Kodaikanal has experienced even more substantial deformation, including shearing and micromelting (Buchwald, 1975). We have observed a variety of shock features in the silicates of Miles, Colomera, Kodaikanal and Weekeroo Station. These include deformation twins, planar fractures and undulatory extinction in pyroxene, and planar fractures and undulatory extinction in large plagioclase grains. These features correspond to shock stage $\mathrm{S} 4$ and post-shock heating of $\sim 300^{\circ} \mathrm{C}$. As 
we discuss later, it is possible that the fine-grained radiating structures and glassy structures with multiple. immiscible liquids also formed as a result of shock, as argued by Osadchii et al. (1981).

\section{${ }^{39}$ Ar ${ }^{+0}$ Ar Chronologies}

The ${ }^{19} \mathrm{Ar}-{ }^{+0} \mathrm{Ar}$ ages and $\mathrm{K} / \mathrm{Ca}$ ratios as a function of cumulative release of ${ }^{39} \mathrm{Ar}$ for the five itradiated meteorite samples are shown in Fig. 3 and Figs. 4a-d. Quoted age uncertainties include all analytical ' sources of error, including uncertainty in the $J$ value, but not the uncertainty in the age of the homblende flux monitor, which is estimated at $\leq 0.5 \%$. Here we discuss some of the characteristics of these age spectra and present our preferred Ar-Ar degassing age for each. In the following section we compare these new Ar-Ar ages with previous radiometric ages of these meteorites, where such data exists. Table 2 summarizes our preferred Ar-Ar age for each meteorite analyzed along with literature data on IIEs.

Watson: The release profiles of ${ }^{39} \mathrm{Ar}-{ }^{40} \mathrm{Ar}$ ages and $\mathrm{K} / \mathrm{Ca}$ ratios for the whole rock sample of Watson (Fig. 3) suggest significant amounts of recoil redistribution of ${ }^{39} \mathrm{Ar}$ among phases. When ${ }^{39} \mathrm{Ar}$ is produced in the reactor by the n,p reaction on ${ }^{39} \mathrm{~K}$ it undergoes a recoil of $\sim 0.16 \mu \mathrm{m}$ (Onstott et al., 1995), which can produce a net transfer of ${ }^{39} \mathrm{Ar}$ from grain surfaces with higher $\mathrm{K}$ to those with lower $\mathrm{K}$. Ar-37 produced by the reaction ${ }^{40} \mathrm{Ca}(\mathrm{n} . \alpha){ }^{37} \mathrm{Ar}$ recoils an even greater distance. In Watson, changes in the $\mathrm{K} / \mathrm{Ca}$ ratio and $\mathrm{Ar}-\mathrm{Ar}$ ages with temperature show three "regimes" at $\sim 0-17 \%, \sim 17-82 \%$, and $>82 \%$ of the total "Ar release, indicating that three different structural or mineral "phases" control the release of ${ }^{39} \mathrm{Ar},{ }^{40} \mathrm{Ar}$, and ${ }^{37} \mathrm{Ar}$. We attribute the peak in $\mathrm{Ar}$-Ar ages at $-2-17 \%$ of the ${ }^{39} \mathrm{Ar}$ release to recoil loss of ${ }^{39} \mathrm{Ar}$ from surfaces of $\mathrm{K}$-rich grains, and the lower Ar-Ar ages at $>82 \%{ }^{39} \mathrm{Ar}$ release to gain of this recoiled ${ }^{\$ 9} \mathrm{Ar}$ by phases with lower $\mathrm{K} / \mathrm{Ca}$ ratios. This redistribution of recoiled ${ }^{39} \mathrm{Ar}$ between phases causes the apparent Ar-Ar ages to increase and decrease for lower and higher temperature extractions, respecturey. (The lower age for the first extraction $\left(0-2 \%{ }^{39} \mathrm{Ar}\right.$ release) we attribute to diffusive loss of ${ }^{40} \mathrm{Ar}$.) Olsen et al. (1994) describe the clear feldspar in Watson as an antiperthite consisting of fine exsolution lamellae of orthoclase-rich feldspar (with $[\mathrm{K}]=5.7 \%$ and a $\mathrm{K} / \mathrm{Ca}$ ratio of $\sim 28$ ) that have exsolved from albitic feldspar. The $\mathrm{K} / \mathrm{Ca}$ of the albite is $\sim 2.3$. The average $\mathrm{K} / \mathrm{Ca}$ of extractions with ${ }^{39} \mathrm{Ar}$ releases of $\sim 11-70 \%$ is also 2.3 . The bulk $\mathrm{K} / \mathrm{Ca}$ ratio of 0.14 reported for Watson by Olsen et al. (1994) is nearly identical to our overall ratio of 0.16 . Pyroxenes in Watson are variable in composition, but some have $\mathrm{Ca}$ concentrations as large as $\sim 13.5 \%$ and vanishingly small $\mathrm{K} / \mathrm{Ca}$ ratios (Olsen et al., 1994). It is the juxtaposition of phases with such extreme $\mathrm{K} / \mathrm{Ca}$ ratios that produces the relatively large Ar recoil effects in Watson.

That $\mathrm{Ar}$ which degassed over nine extractions between $\sim 17-82 \%$ of the total ${ }^{39} \mathrm{Ar}$ release gives a constant Ar-Ar "plateau" age of $3.653 \pm 0.012 \mathrm{Gyr}$ ( $2 \sigma$ of the mean). The deficiency of ${ }^{39} \mathrm{Ar}$ in the $2-17 \%$ 
release (relative to the plateau age) is equal to the excess of ${ }^{39} \mathrm{Ar}$ in the $82-100 \%$ release (within a few percent), which indicates that ${ }^{39} \mathrm{Ar}$ was not lost from the bulk sample during recoil. This agreement implies that the "plateau" age in the middle portion of the ${ }^{39}$ Ar release, which derives from the interiors of feldspar grains, was not affected by ${ }^{39} \mathrm{Ar}$ recoil redistribution. Thus, we interpret the $3.653 \mathrm{Gyr}$ age to be the time of last major Ar degassing of Watson silicate. The total ${ }^{39} \mathrm{Ar}-{ }^{40} \mathrm{Ar}$ age for this Watson sample (summed over all Extractions except the first) has an identical value of 3.655 Gyr. This agreement of total and plateau ages further suggests that little radiogenic ${ }^{40}$ Ar has been lost since the 3.65 Gyr resetting event.

Techado: Silicate from Techado whole rock contains $\mathrm{K}$ at chondritic levels. The $\mathrm{K} / \mathrm{Ca}$ ratio decreases throughout the extraction and suggests overlap in Ar degassing from at least two different lattice sites (Fig. 4a). Some extractions above $~ 70 \%$ of the total ${ }^{39} \mathrm{Ar}$ release show slightly lower Ar-Ar ages and suggest possible weathering loss of radiogenic ${ }^{40} \mathrm{Ar}$ from grain surfaces of the phase with low $\mathrm{K} / \mathrm{Ca}$. Alternatively, these Ar releases may show gain of recoil ${ }^{39} \mathrm{Ar}$, but the source of such recoil ${ }^{39} \mathrm{Ar}$ is not apparent in the low-temperature releases (e.g., compare with Watson). Four of five extractions releasing $-5-70 \%$ of the ${ }^{39} \mathrm{Ar}$ from Techado suggest an ${ }^{39} \mathrm{Ar}-{ }^{+9} \mathrm{Ar}$ plateau age of $4.49 \pm 0.01 \mathrm{Gyr}$.

Miles: Both changes in the $\mathrm{K} / \mathrm{Ca}$ ratio (Fig. $4 \mathrm{~b}$ ) and the rate of ${ }^{39} \mathrm{Ar}$ release from Miles suggest a significant change in the phases degassing $\mathrm{Ar}$ at about $75 \%$ of the total ${ }^{39} \mathrm{Ar}$ release. Grain sites releasing between $\sim 0-16 \%$ of the total ${ }^{39} \mathrm{Ar}$ indicate some prior diffusive loss of radiogenic ${ }^{40} \mathrm{Ar}$. However, five extractions releasing $\sim 16-63 \%$ of the total ${ }^{39} \mathrm{Ar}$ give a plateau age of $4.412 \pm 0.016 \mathrm{Gyr}(2 \sigma)$. The phase with lower $\mathrm{K} / \mathrm{Ca}$ degassing Ar at higher temperatures shows slightly lower Ar-Ar ages. We interpret this decrease in age to be caused by gain of recoiled ${ }^{39} \mathrm{Ar}$, whose source was in the low-temperature phase that has lost ${ }^{10} \mathrm{Ar}$. The total age above $15 \%{ }^{39} \mathrm{Ar}$ release is $4.39 \mathrm{Gyr}$ and would be a firm lower limit to the time of last major Ar degassing.

Colomera: For the sample of Colomera feldspar, the $\mathrm{K} / \mathrm{Ca}$ ratio is relatively constant across most of the Ar release but shows an unusual amount of fine-scale variation (Fig. 4c). No obvious features of ${ }^{39} \mathrm{Ar}$ recoil redistribution exist in the age spectrum. Some diffusive loss of radiogenic ${ }^{40} \mathrm{Ar}$ is indicated over $\sim 0-25 \%$ of the total ${ }^{39} \mathrm{Ar}$ release. The average ${ }^{39} \mathrm{Ar}-{ }^{40} \mathrm{Ar}$ age for all extractions above $\sim 25 \%{ }^{39} \mathrm{Ar}$ release is $4.48 \mathrm{Gyr}$. However, the Ar-Ar age spectrum tends to increase with increasing ${ }^{39} \mathrm{Ar}$ release. Ten extractions releasing $\sim 25-72 \%$ of the total ${ }^{39} \mathrm{Ar}$ gives an age of $4.469 \pm 0.012 \mathrm{Gyr}(2 \sigma)$, with all 10 extractions giving ages lying within $2 \sigma$ of this mean value. On the other hand, the last several extractions show ages up to $\geq 4.50 \mathrm{Gyr}$ (Appendix 1). (The $1550^{\circ} \mathrm{C}$ extraction had significant blank corrections and is unreliable, but we find no reason to suspect the $4.55 \mathrm{Gyr}$ age of the $1450^{\circ} \mathrm{C}$ extraction. These two extractions released the last $0.1 \%$ of the total ${ }^{39} \mathrm{Ar}$.) We have observed similar sloped Ar-Ar 
age spectra in mesosiderites (Bogard and Garrison. 1998) and in silicate from the Caddo County IAB iron (Takeda et al.. 1999), and we interpret these as arising from the K-Ar chronometer being partially open dunng relatively slow cooling within the parent body. Alternatively, the original K-Ar age of Colomera feldspar was $>4.5 \mathrm{Gyr}$, and may have been reset by impact heating $\sim 4.47 \mathrm{Gyr}$ ago.

Sombrerete: Both the $\mathrm{K} / \mathrm{Ca}$ and $\mathrm{Ar}$-Ar age spectra for Sombrerete silicate are relatively cbinstant with extraction temperature (Fig. 4d). Except for the first $\sim 2 \%$ of the total ${ }^{39} \mathrm{Ar}$ release, the K/Ca ratio shows a steady decrease by a factor of $\sim 2$ throughout the extraction. A small amount of diffusive loss of radiogenic ${ }^{40} \mathrm{Ar}$ is indicated for the first few extractions, which have higher $\mathrm{K} / \mathrm{Ca}$ ratios. Three extractions at $-3-11 \%{ }^{39}$ Ar release show a small peak in age indicating that $\sim 0.1 \%$ of the total ${ }^{39} \mathrm{Ar}$ has experienced recoil loss. The lower age of the $1550^{\circ} \mathrm{C}$ extraction suggests that it gained recoiled ${ }^{39} \mathrm{Ar}$, but this extraction suggest all of the ${ }^{39} \mathrm{Ar}$ that apparently recoiled. The total ${ }^{39} \mathrm{Ar}-{ }^{40} \mathrm{Ar}$ age considering all extractions is $4.53 \mathrm{GyT}$, and would be an approximate lower limit for the time of last major Ar degassing. The summed Ar-Ar age over those 13 extractions showing an age plateau $\left(775-1350^{\circ} \mathrm{C}\right)$, which released $87 \%$ of the total ${ }^{39} \mathrm{Ar}$, is $4.535 \pm 0.008 \mathrm{Gyr}(2 \sigma)$. There appears to be a very slight decrease in age $(\sim 0.2 \%)$ across these 13 extractions, which may have arisen from some detail of the ${ }^{39} \mathrm{Ar}$ redistribution process that is not obvious. However, this age decrease, if real, is less than the age uncertainty assigned above. Thus, we conclude that the last time of major Ar degassing for Sombrerete occurred 4.535 \pm 0.008 Gyt ago.

\section{Space Exposure Ages}

Literature data on cosmogenic noble gases in IIE meteorites is sparse. Table 3 presents our results on $\mathrm{He}, \mathrm{Ne}$, and $\mathrm{Ar}$ released in $400^{\circ} \mathrm{C}$ and melt $\left(1550^{\circ} \mathrm{C}\right)$ extractions of unirradiated silicate samples from Netschaëvo, Sombrerete, Miles, and Colomera feldspar. We examined the cosmic-ray (space) exposure ages of IIE meteorites to determine if the three meteorites with the youngest radiometric ages of $\sim 3.67$ Gyr had different exposure ages compared to the other IIEs, as previously suggested by Casanova et al. (1995). If that were the case, it might be suggestive of derivation of the three young IIEs from a different part of the parent body via a different impact event. General experimental techniques are described in Garrison and Bogard (1998). Space exposure ages for these four meteorites, along with literature data for additional IIE meteorites, are estimated in Table 4.

Calculation of space exposure ages for most of these IIE meteorites is not straightforward because of uncertainties in the production rates of the cosmogenic noble gases. The ${ }^{21} \mathrm{Ne}$ and ${ }^{38} \mathrm{Ar}$ production rates depend on three major factors: the effects of sample shielding; the chemical composition of the meteorite: and assumptions made about the relative importance of various elements in producing 
cosmogenic gases. Cosmogenıc 'He is much less sensitive to variations in chemistry and shielding, but sometimes it is lost from the meteorite by diffusion. Shielding differences among samples are often normalized using the cosmogenic " $\mathrm{Ne} ;=\mathrm{Ye}$ ratio. Values of this ratio for the four silicate analyses reported here were $0.98-1.01$. The $400^{\circ} \mathrm{C}$ extractions give substantially lower ${ }^{2} \mathrm{Ne} / 22 \mathrm{Ne}$ than the melt extractions, probably due to preferential release of Ne produced from low energy reactions on $\mathrm{Na}$. , However, the amounts of $\mathrm{Ne}$ released in the $400^{\circ} \mathrm{C}$ extractions were small compared to the total $\mathrm{Ne}$ amounts. The tótal ${ }^{21} \mathrm{Ne} /{ }^{22} \mathrm{Ne}$ ratios measured for all four meteorites are significantly larger than those expected or observed in even the largest ordinary chondrites (Graf et al., 1990; Garrison et al., 1992). Similar ${ }^{21} \mathrm{Ne} /{ }^{22} \mathrm{Ne}$ ratios of $\sim 1.0$ are observed in silicates from mesosiderites and some other iron meteorites and have been attributed to an enhanced production of secondary neutrons over secondary protons in the metal matrix (Jentsch and Schultz, 1996). Such an effect makes it difficult to use $\because \because \mathrm{Ve} /{ }^{21} \mathrm{Ne}$ as a shielding indicator. Consequently, we made no shielding corrections to the IIE silicate data.

A second possible error in deriving cosmogenic production rates for IIE silicates derives from uncertainties in the chemical composition of the samples. Silicates from IIEs show a rather wide variation in mineralogy and composition (Mittlefehldt et al., 1998). As discussed earlier, Netschaëvo and Techado silicates are less differentiated and have compositions similar to those of $\mathrm{H}$-chondrites (Bunch et al., 1970; Olsen and Jarosewich, 1971; Bild and Wasson, 1977; Casanova et al.,1995). Watson silicate may originally have had a composition similar to $\mathrm{H}$-chondrites, but it has lost most of its metal and sulfur (Olsen et al., 1994). Absence of chondritic metal not only lowers the Fe concentration but also increases the concentration of other target elements for cosmogenic Ne and Ar production (e.g., $\mathrm{Mg}$, $\mathrm{Si}$, and $\mathrm{Ca}$ ) relative to the composition of chondrites. Miles and Sombrerete also are devoid of metal and have compositions quite different from those of $\mathrm{H}$-chondrites. For these two meteorites we used the chemical compositions reported by Ikeda and Prinz (1996) and Prinz et al. (1982), respectively.

A third uncertainty in deriving cosmogenic production rates lies in selecting the absolute production rate factors for each nuclide. Eugster (1988) determined the absolute ${ }^{21} \mathrm{Ne}$ and ${ }^{38} \mathrm{Ar}$ production rates for H-chondrites by using the relative chemical element factors reported by Schultz and Freundel (1985) and Freundel et al. (1986) and then normalizing these rates to ${ }^{81} \mathrm{Kr}-\mathrm{Kr}$ exposure ages for several chondrites. The ${ }^{38} \mathrm{Ar}$ production rates for chondrites was later revised downward by $\sim 11 \%$ (Graf and Marti, 1995). Because Netschaëvo silicate has a composition similar to $\mathrm{H}$-chondrites, we used these $\mathrm{H}$-chondrite production rates to calculate the ages in Table 4. In a second method of determining absolute production rates, Eugster and Michel (1995) used similar chemical element factors as Schultz and Freundel (1985), but normalized the cosmogenic ${ }^{3} \mathrm{He},{ }^{21} \mathrm{Ne},{ }^{38} \mathrm{Ar}$, and ${ }^{81} \mathrm{Kr}-\mathrm{Kr}$ data separately for suites of eucrites and 
diogenites. This second methoc gives the option of calculating production rates by varying the chemical compositions. Applying this second method to the Netschaëvo data gives essentially the same exposure ages. We attribute the lower : He age compared to the ${ }^{21} \mathrm{Ne}$ and ${ }^{38} \mathrm{Ar}$ ages to diffusive loss of ${ }^{3} \mathrm{He}$. Netschaëvo was apparently forged. which would certainly contribute to $\mathrm{He}$ loss, and the ${ }^{4} \mathrm{He}$; concentration of Netschaëvo appears low as well (Table 3). Some ${ }^{21} \mathrm{Ne}$ may have been lost. Wé suggest that the higher ${ }^{38}$ age of $18 \mathrm{Ma}$ that Niemeyer, (1980) reported for an irradiated sample of Netschaëvo may have been caused by ${ }^{38} \mathrm{Ar}$ produced from neutron capture on ${ }^{37} \mathrm{Cl}$ in the reactor, a possibility also mentioned by the author.

Because the chemical compositions of Miles and Sombrerete are not chondritic, the method of Eugster and Michel (1995) was used to calculate production rates for these meteorites. We used the rates determined for eucrites as opposed to that for diogenites, which would be $\sim 8 \%$ lower for ${ }^{21} \mathrm{Ne}$. For ${ }^{21} \mathrm{Ne}$ production we added in an additional factor for $\mathrm{Na}$ (Hohenberg et al., 1978), which exists in considerably greater abundance than in eucres. The $\mathrm{Ca}$ concentrations determined for our irradiated samples of Miles and Sombrerete were considerably lower than those reported by Ikeda and Prinz (1996) and Prinz et al. (1982). Consequently, we give two values for the ${ }^{38} \mathrm{Ar}$ ages for Miles and Sombrerete (Table 4). The first entry assumes the literature $\mathrm{Ca}$ values, and the second entry assumes the $\mathrm{Ca}$ values we determined on irradiated samples. The ${ }^{3} \mathrm{He}$ and ${ }^{21} \mathrm{Ne}$ ages are essentially the same for either $\mathrm{Ca}$ value. The much closer agreement between ${ }^{21} \mathrm{Ne}$ and ${ }^{38} \mathrm{Ar}$ ages for Miles using our determined Ca (218 Ma) suggests that this value is more appropriate. For Sombrerete, the ${ }^{38} \mathrm{Ar}$ ages are much higher compared to the ${ }^{3} \mathrm{He}$ and ${ }^{21} \mathrm{Ne}$ ages using either $\mathrm{Ca}$ abundance. The Sombrerete ${ }^{38} \mathrm{Ar}$ abundance is unlikely to be in error, because similar cosmogenic ${ }^{38} \mathrm{Ar}$ and radiogenic ${ }^{40} \mathrm{Ar}$ concentrations were measured for the neutron-irradiated sample. Only if we assume the Ca concentration in our unirradiated sample was $-12 \%$, or considerably larger than that we measured in the irradiated sample or that reported by Prinz et al. (1982), would the ${ }^{21} \mathrm{Ne}$ and ${ }^{29} \mathrm{Ar}$ ages for Sombrerete become concordant. We considered the possibility that excess ${ }^{38} \mathrm{Ar}$ was acquired from the surrounding metal phase (individual silicate particles of Sombrerete were only $\sim 10-50 \mathrm{mg}$ in size), but the acquired amount would have to be large.

Alternatively, Sombrerete may have lost both ${ }^{3} \mathrm{He}$ and ${ }^{21} \mathrm{Ne}$ by diffusion. Thus, we consider the ${ }^{21} \mathrm{Ne}$ age for Sombrerete to be a lower limit for its space exposure time.

Our irradiated sample of Colomera gave $[\mathrm{Ca}]=3.39 \%$ and $[\mathrm{K}]=13.0 \%$. This $\mathrm{K}$ is almost as large as the pure orthoclase concentration of $14 \%$ and indicates that $\mathrm{Mg}$ and $\mathrm{Fe}$ are essentially absent. For Colomera $\mathrm{Al}$ and $\mathrm{Si}$ abundances. we adopted the chemical composition reported for feldspar by Bunch and Olsen (1968). The relative elemental factors for calculating ${ }^{38} \mathrm{Ar}$ production rates originally used $\mathrm{K} / \mathrm{Ca}=7$ derived from mineral separates of the Bruderheim chondrite (Bogard and Cressy, 1973; 
Freundel et al., 1986). However, Eugster and Michel (1995) adopted $\mathrm{K} / \mathrm{Ca}=1.6$, based on data from 1.6 $\mathrm{GeV}$ proton irradiation of a silicate target. The very large $\mathrm{K}$ in Colomera feldspar presents an opportunity to compare the two different $\mathrm{KCa}$ production ratios for ${ }^{38} \mathrm{Ar}$. Using $\mathrm{K} / \mathrm{Ca}=1.6$ in the method of Eugster and Michel (1995) gives for Colomera feldspar an ${ }^{38} \mathrm{Ar}$ age of $103 \cdot \mathrm{Myr}$ and a ${ }^{21} \mathrm{Ne}$ age of $35 \mathrm{Myr}$. The low : He age indicates diffusive loss, as might be expected for He in feldspar. $\mathrm{K} / \mathrm{Ca}=7$ in the production equation gives an ${ }^{38} \mathrm{Ar}$ age of $27 \mathrm{Myr}$ using the chemical equations of Eugster and Michel (1995) and $31 \mathrm{My}$ using the equations of Schultz and Freundel (1985). Thus, the use of K/Ca $=7$ in the production equation gives much better agreement between ${ }^{38} \mathrm{Ar}$ and ${ }^{21} \mathrm{Ne}$ ages than the 1.6 ratio used by Eugster and Michel (1995). This comparison suggests that the higher $\mathrm{K} / \mathrm{Ca}$ production ratio is preferable. (The ${ }^{38} \mathrm{Ar}$ ages for Sombrerete in Table 4 also were calculated using a $\mathrm{K} / \mathrm{Ca}$ production ratio of 7 ; the ${ }^{38} \mathrm{Ar}$ ages calculated using a ratio of 1.6 would be considerably larger.)

The Watson exposure ages given in Table 4 are from Olsen et al. (1994) and apparently were calculated using the method of Eugster and Michel (1995) and the chemical composition determined in that study. The Techado silicate exposure ages were calculated from two analyses reported by Casanova et al (1995) using the $\mathrm{H}$-chondrite production rates of Eugster (1988). The ${ }^{38} \mathrm{Ar}$ age calculated from our irradiated sample would be $\sim 45 \mathrm{Ma}$ (assuming all ${ }^{38} \mathrm{Ar}$ is cosmogenic). The ${ }^{38} \mathrm{Ar}$ age for Techado metal was calculated by Casanova et al. (1995) and used production rates derived from ${ }^{40} \mathrm{~K}$ and ${ }^{36} \mathrm{Cl}$. The space exposure ages listed for Kodaikanal and Weekeroo Station are calculated from cosmogenic noble gases in the metal phase. Cosmogenic noble gas ratios for Kodaikanal metal indicate irradiation near the meteoroid surface (e.g., Signer and Nier, 1960) and probably give a reliable exposure age of 12-15 Myr (Bogard et al., 1969). However, cosmogenic noble gas ratios for Weekeroo Station metal are not wellbehaved, and the production rates are more uncertain. We used the Weekeroo Station metal noble gas concentrations and the Kodaikanal metal production rates given by Bogard et al. (1969) to calculate the Weekeroo Station exposure age in Table 4. Significantly greater shielding compared to Kodaikanal would make these Weekeroo Station ages even older. Niemeyer (1980) reported ${ }^{38} \mathrm{Ar}$ and ${ }^{126} \mathrm{Xe}$ ages for Weekeroo Station silicate of 350-930 Ma.

Watson, Kodaikanal, and Netschaëvo all have relatively short space exposure ages. These ages are similar to those for many $\mathrm{H}$-chondrites, which show a strong exposure age peak at 5-10 Myr (Graf and Marti, 1995), as pointed out by Olsen et al. (1994) for Watson. Given the uncertainties in sample composition and shielding, the exposure ages of Watson and Kodaikanal could be the same. The exposure age for Netschaëvo, $\sim 3 \mathrm{Myr}$, seems distinctly younger, but we cannot rule out the possibility of extreme shielding or a secondary breakup in space. These three IIE meteorites also all have young radiometric ages (Table 2), and it is possible (but not required) that they were ejected from a single 
locale on their parent body by a single cratering event. The other five IIE meteorites indicate a spread of space exposure ages that are all considerably older. Exposure ages for Colomera and Techado are probably at least $-35 \mathrm{Myr}$, and the Weekeroo Station age is probabiy several hundred Myr. Thus, we suggest that in addition to their young radiometric ages. Watson, Kodaikanal, and Netschaëvo also may possess the common characteristic of having been derived from a different portion of the IIE pạtent body compared to other IIE meteorites. Niemeyer (1980) suggested a different parent body altogether. This may be a factor in why these three alone among the IIEs show reset isotopic ages. These young IIE exposure ages also are lower than ages for other silicate-bearing iron meteorites. For example, Niemeyer (1979) calculated ${ }^{38} \mathrm{Ar}$ exposure ages of $\sim 130-480 \mathrm{Ma}$ for silicate from several IAB meteorites, using Ar measured in irradiated samples and an assumed production rate of $2.4 \times 10^{-8} \mathrm{~cm}^{3} / \mathrm{g}-\mathrm{Ca} / \mathrm{Myr}$.

\section{Cosmogenic Xenon}

The isotopic abundances of $\mathrm{Xe}$ in the melt extractions of four IIE silicate samples are dominated by a cosmogenic component and are given in Table 5. (Smaller Xe amounts released in the $400^{\circ} \mathrm{C}$ extractions were apparently dominated by terrestrial Xe and were not measured in detail.) We assume that the trapped Xe component in these meteorites has the composition of CI chondrites (Pepin, 1991). We normalize the $\mathrm{Xe}$ isotopic composition to ${ }^{136} \mathrm{Xe}$ and subtract out this trapped component, assuming all ${ }^{136} \mathrm{Xe}$ is trapped. The remaining $\mathrm{Xe}$ is mostly cosmogenic. The isotopic composition of this cosmogenic Xe, normalized to ${ }^{126} \mathrm{Xe}=1.0$, is plotted in Fig. 5 for the three IIE samples that showed the largest cosmogenic excesses. ${ }^{129} \mathrm{Xe}$ is not plotted because of the obvious presence in Sombrerete and Colomera of ${ }^{129} \mathrm{Xe}$ from the decay of extinct ${ }^{129} \mathrm{~T}$. Residual excesses in ${ }^{134} \mathrm{Xe}$ are small and could represent uncertainties in the composition of the assumed trapped component. Also plotted in Fig. 5 are the cosmogenic Xe spectra reported for Weekeroo Station (Bogard et al., 1971a) and the Stannern eucrite (Marti et al., 1966). The plotted cosmogenic Xe spectra for the IIEs are generally similar. It is not clear why Miles shows a different spectrum at masses 130 and 132, but this may be due in part to the presence of a residual terrestrial component.

The relative production of cosmogenic ${ }^{131} \mathrm{Xe}$ can be enhanced under large shielding conditions due to thermal neutron capture by ${ }^{130} \mathrm{Ba}$. Because IIE silicates were irradiated in an extensive matrix of metal, and because Fe is a strong absorber of epithermal neutrons, we might expect that the relative yield of cosmogenic ${ }^{131} \mathrm{Xe}$ would be lower in IIE silicate than in other silicate samples irradiated under moderate shielding. The relative yield of ${ }^{|3|} \mathrm{Xe}$ is slightly larger in the Stannem eucrite compared to the IIE meteorites (excepting Miles, whose excess ${ }^{131} \mathrm{Xe}$ has a large uncertainty). In addition, lunar regolith samples, which were irradiated under a wide range of shielding conditions, give considerably larger 
cosmogenic ${ }^{131} \mathrm{Xe} /{ }^{126} \mathrm{Xe}$ of $\sim 4-8$ (Bogard et al. 1971b). We suggest that the value of cosmogenic $1: i \mathrm{Xe} /{ }^{126} \mathrm{Xe}$ of -3.2 observed in three of the IIE samples demonstrates irradiation under relatively large shielding and is an approximate lower limit to cosmogenic Xe produced in the absence of a significant thermal neutron capture component.

\section{COMPARISON OF IIE RADIOMETRIC AGES}

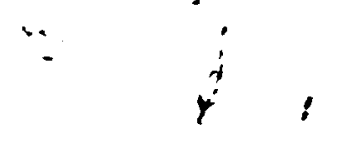

Little precise age data existed for the meteorites analyzed here when we began our study (Table 2). Olsen et al. (1994) reported the $\mathrm{K}$ and ${ }^{40} \mathrm{Ar}$ concentrations in separate samples of Watson silicate and calculated a classical K- ${ }^{40} \mathrm{Ar}$ age of $3.5 \mathrm{Gyr}$. Casanova et al. (1995) reported a classical K- ${ }^{40} \mathrm{Ar}$ age of 4.6 Gyr for Techado. Sanz et al. (1970) reported a ${ }^{87} \mathrm{Rb}^{87} \mathrm{Sr}$ isochron age for Colomera silicate of $4.61 \pm 0.04$ Gyr. We assume that the Colomera age was calculated with a ${ }^{87} \mathrm{Rb}$ decay constant of $1.39 \times 10^{-11} \mathrm{yr}^{-1}$ in general use before 1977 . Using the currently recommended $\lambda$ decay constant of $1.42 \times 10^{-11}$ (Steiger and Jäger, 1977), the age becomes $4.51 \pm 0.04$ Gyr. Snyder et al. (1998) recently reported model-dependent, whole-rock Sm-Nd ages of 3.0 Gyr and 4.27 Gyr for single inclusions from Watson and Miles. To our knowledge, no isotopic ages have been reported for Sombrerete.

Isotopic ages have been reported for silicate from some other IIE iron meteorites (Table 2). Niemeyer (1980) reported ${ }^{39} \mathrm{Ar}-{ }^{40} \mathrm{Ar}$ ages of $4.49 \pm 0.03 \mathrm{Gyr}$ for Weekeroo Station and $3.745 \pm 0.03 \mathrm{Gyr}$ for Netschaëvo. (The reported Ar-Ar ages were reduced by a factor of 0.988 to compensate for a change in the determined age of the St. Severin age monitor used in Niemeyer's analyses; Herpfer et al., 1994.) Classical K-Ar ages of $\sim 4.3$ Gyr were obtained on a separate Weekeroo Station silicate inclusion (Bogard et al., 1968). Niemeyer (1980) reported a I-Xe age for Weekeroo Station that is 11 Myr younger than Bjurböle and several Myr younger than I-Xe ages on silicate from some IAB iron meteorites. Bumett and Wasserburg (1967b) analyzed whole rock and mineral (density) separates from a composite of 13 inclusions from Weekeroo Station and reported $\mathrm{a}^{87} \mathrm{Rb}^{8}{ }^{87} \mathrm{Sr}$ isochron age of $4.28(+0.23,-0.12) \mathrm{Gyr}$ (recalculated using $\lambda^{87} \mathrm{Rb}$ of $1.42 \times 10^{-11}$ ). From four silicate inclusions of Weekeroo Station, Evensen et al. (1979) derived $\mathrm{a}^{87} \mathrm{Rb}-{ }^{87} \mathrm{Sr}$ isochron age of $4.39 \pm 0.07$ Gyr.

Kodaikanal silicate has a ${ }^{87} \mathrm{Rb}-{ }^{87} \mathrm{Sr}$ isochron age of $3.7 \pm 0.1 \mathrm{Gyr}$ (Burnett and Wasserburg, 1967a; age recalculated from the reported age of $3.8 \mathrm{Gyr}$ ) and a classical $\mathrm{K}-{ }^{40} \mathrm{Ar}$ age of $\sim 3.4 \mathrm{Gyr}$ (Bogard et al., 1969). The $\mathrm{Pb}-\mathrm{Pb},{ }^{238} \mathrm{U}-\mathrm{Pb}$, and ${ }^{235} \mathrm{U}-\mathrm{Pb}$ ages for Kodaikanal are $3.676 \pm 3,3.680 \pm 5$, and $3.679 \pm 5 \mathrm{Myr}$, respectively (Göpel et al., 1985). The $\mathrm{Rb}-\mathrm{Sr}$ data for Kodaikanal indicate that chemical fractionation occurred at this time. On the other hand, ${ }^{187} \mathrm{Re}-{ }^{187} \mathrm{Os}$ data for Kodaikanal metal lie on the same 4.6 Gyr isochron as several other-iron meteorites (Birck and Allègre, 1998) and suggest that the Re-Os chronometer was not reset. Analysis of tungsten isotopes in Watson metal also indicates that the short- 
lived ${ }^{182} \mathrm{Hf}-{ }^{182} \mathrm{~W}$ chronometer was not reset by the -3.7 Gyr event (Snyder et al., 1998). In addition to these IIE ages, silicates from five IAB iron meteontes have given ${ }^{39} \mathrm{Ar}-{ }^{10} \mathrm{Ar}$ ages of $4.45-4.53 \mathrm{Gyr}$ (Niemeyer. 1979; Takeda et al., 1999).

Young Age Group: Radiometric ages of silicate from three IIE meteorites, Wàtson, Kodaikanal, and Netschaëvo, (determined by three techniques in the case of Kodaikanal) are $-3.65-3.75$ Gyt (Table 2). In addition, NTemeyer (1980) found a lack of I-Xe correlation for Netschaëvo, consistent with an age younger than $-4.45 \mathrm{Gyr}$. The three most precise ages (the Ar-Ar ages for Watson and Netschaëvo and the $\mathrm{Pb}-\mathrm{Pb}$ age for Kodaikanal) are similar but do not overlap within their stated uncertainties. An important question is whether these younger ages are the same, indicating resetting in a common event, or are distinctly different, requiring separate events. The two Ar-Ar ages depend on the accuracy of the age of a standard sample irradiated with the IIE samples, and these standard samples were different for Watson and Netschaëvo. The NL-25 hornblende irradiated with Watson has a totally flat Ar-Ar release spectrum. and its age of $2.65 \mathrm{Gyr}$ is believed known to $\pm 0.5 \%$ (Bogard et al., 1995). St. Severin would appear to be a less accurate irradiation standard. The absolute ${ }^{129} \mathrm{I}-{ }^{129} \mathrm{Xe}$ age of St Severin feldspar was determined to be 4.558 Gyr (Brazzle et al., 1999). The K-Ar age of Saint Severin was assumed to be $4.425 \pm 0.019$ Gyr by Niemeyer $(1979 ; 1980)$, and his reported age for Netschaëvo was $3.79 \pm 0.03$ Gyr. However, later Ar-Ar analyses of four St. Severin samples by Hohenberg et al. (1981) and Treiloff et al. (1989) gave limited "plateau" ages of $4.42,4.38,4.35$, and 4.34 Gyr. In their consideration of Niemeyer's data. Herpfer et al. (1994) adopted a St. Severin age of $4.373 \pm 0.030 \mathrm{Gyr}$, the average of these four new analyses. This is the St. Severin age we used to correct the Netschaëvo and Weekeroo Station Ar-Ar ages reported in Table 2. However, the apparent Ar-Ar ages for St. Severin are not constant with extraction temperature, making a precise determination of the St. Severin age both difficult and dependent on the temperature range utilized. In their original calibration of St. Severin as an irradiation age monitor, Alexander and Davis (1974) used a single extraction of $800-1600^{\circ} \mathrm{C}$. Niemeyer (1979) based his determination of the irradiation constant on several $900-1450^{\circ} \mathrm{C}$ extractions of St Severin, but did not report his St. Severin data. In the two St. Severin analyses reported by Hohenberg et al. (1981), this temperature range yields Ar-Ar ages showing a broad spread of 4.21-4.45 Gyr, and the Ar-Ar ages spread over 0.4 Gyr for all of the St. Severin extractions. Further, because St. Severin experienced parent body metamorphism, its ${ }^{39} \mathrm{Ar}-{ }^{43} \mathrm{Ar}$ age probably cannot be directly compared with ages of chondrites determined by other radiometric techniques, as was originally done by Alexander and Davis (1974). We conclude, therefore, that the uncertainty in the Ar-Ar age of the St. Severin irradiation monitor is sufficiently great such that the uncertainty in the Ar-Ar age of Netschaëvo likely overlaps the 3.65 Gyr Ar-Ar age for Watson. 
The determined Ar-Ar age of Watson and the $\mathrm{Pb}-\mathrm{Pb}$ age of Kodaikanal differ by only $23 \mathrm{Myr}$, but this is greater than their combined $2 \sigma$ uncertainties. However, this difference is comparable to the accuracy of the age of the ..LG-25 homblende monitor, and it is only moderately greater than the absolute uncertainty in $\mathrm{Ar}$-.tr age produced by uncertainties in the $\mathrm{K}$ decay constants.(McCoy et.al., 1996). Thus, we conclude that it is very possible (but not required) that the Watson, Kodaikand, and: Netschaëvo IIE sificates have the exact same radiometric age of $\sim 3.67 \mathrm{Gyr}$ and were reset by a common event. The oldér Re-Os age for Kodaikanal metal and the W isotopic data for Watson metal demonstrate that the metal in IIEs formed early and did not equilibrate with silicate during the process that produced the younger ages of three of the IIEs. However, because Re and Os essentially are only taken up by metal, even during significant secondary heating, the Re-Os age of Kodaikanal is not sensitive to silicate resetting (Birck and Allègre, 1998).

Old Age Group: Silicate from the other five IIE meteorites all show much older radiometric ages of $\geq 4.28 \mathrm{Gyr}$. The reported Ar-Ar ages for Colomera, Techado, and Weekeroo Station and the Rb-Sr age for Colomera overlap within their respective uncertainties (Table 2). The Ar-Ar "plateau" age for Colomera appears slightly younger than its $\mathrm{Rb}-\mathrm{Sr}$ age, but the Ar-Ar age observed in high temperature extractions is nearly the same as the Rb-Sr age. However, it seems doubtful that the $\mathrm{K}$-Ar age of all five IIEs with old ages (Colomera, Techado, Weekeroo Station, Sombrerete and Miles) all closed at the same time. The Ar-Ar ages reported here for these five meteorites suggest an age spread of $\sim 0.12 \mathrm{Gyr}$, with Sombrerete being the oldest and Miles the youngest. The Ar-Ar age for Sombrerete ranks among the oldest precise Ar-Ar ages determined for meteorites (Bogard and Garrison, 1999). Further, Sanz et al. (1970) suggested possible evolutionary histories of Colomera and Weekeroo Station from Sr isotopic data. Assuming evolution in a simple system with chondritic $\mathrm{Rb} / \mathrm{Sr} \cong 0.26$, they concluded that Colomera probably isotopically equilibrated $\sim 40 \mathrm{Myr}$ after the time such a system would have a ${ }^{87} \mathrm{Sr} /{ }^{86} \mathrm{Sr}$ intercept equal to $\mathrm{BABI}$; which is an average value for eucrites. The time when ${ }^{87} \mathrm{Sr} /{ }^{86} \mathrm{Sr}=\mathrm{BABI}$ may be given by precise $\mathrm{Pb}-\mathrm{Pb}$ ages of 4.556-4.560 determined for the Ibitira eucrite (Chen and Wasserburg, 1985; Manhes et al., 1987). Thus, the time when ${ }^{87} \mathrm{Sr} /{ }^{86} \mathrm{Sr}$ evolution in a chondritic system would equal that measured in Colomera would be $\sim 4.52 \mathrm{Gyr}$ (assuming $\lambda^{87} \mathrm{Rb}=1.42 \times 10^{-11}$ ). Similarly, Evensen et al. (1979) noted that the Rb-Sr age and initial ${ }^{87} \mathrm{Sr} /{ }^{86} \mathrm{Sr}$ intercept of Weekeroo Station also would be consistent with simple evolution in a system with chondritic $\mathrm{Rb} / \mathrm{Sr}$. In comparing ${ }^{87} \mathrm{Sr} /{ }^{86} \mathrm{Sr}$ among several different Colomera inclusions, Sanz et al. (1970) found no direct evidence for later $\mathrm{Sr}$ equilibration. However, they stated that Sr equilibration could have occurred up to $\sim 0.03$ Gyr after silicate formation. The slightly younger Ar-Ar age could indicate that Colomera cooled sufficiently slowly that the Ar-Ar system remained open to diffusion for a period of $\sim 0.04$ Gyr after the Rb-Sr system 
closed. These considerations suggest that temperatures sufficient to prevent closure of isotopic chronometers existed in parts of the IIE parent body for significant periods of time, which is consistent with petrologic data suggesting relatively slow cooling for differentiated silicates. The cooling rate of Colomera is essentraily unknown, but it is interesting to note that kamacite bandwidths in Colomera $(\sim 0.7 \mathrm{~mm})$ are roughly an order of magnitude higher than those in Kodaikanal $(\sim 100 \mu \mathrm{m})$. Bercé and Burnett (1969) ard Olsen et al. (1994) supported a cooling rate of $\sim 1000^{\circ} \mathrm{C} / \mathrm{Myr}$ for Kodaikanal. The much wider kamacite bands in Colomera suggest a slower cooling rate.

The vanous radiometric ages for Weekeroo Station present something of an enigma. The Weekeroo Station $\mathrm{Ar}$-Ar age, which should be more easily reset, is slightly older than the two $\mathrm{Rb}$-Sr ages. However, the combined uncertainties on these three ages are sufficiently large to be consistent with a single age. If we assume $\lambda^{87} \mathrm{Rb}=1.402 \times 10^{-11}$, as suggested by Birck and Allègre (1978) and Minster et al. (1982), the two determined Rb-Sr ages for Weekeroo Station become $4.34 \mathrm{Gyr}$ and $4.45 \pm 0.03 \mathrm{Gyr}$, in better agreement with the Ar-Ar age. However, the $\mathrm{Rb}$-Sr age for Colomera would then rise to $4.57 \pm$ $0.04 \mathrm{Gyr}$, and the age uncertainty does not quite permit Colomera to be $\sim 40 \mathrm{Myr}$ younger than the $\mathrm{Pb}-\mathrm{Pb}$ age of Ibitira. as discussed above. Even more difficult to understand are Sm-Nd model ages of $0.7 \mathrm{Gyr}$ reported by Snyder et al. (1998) for whole rock analyses of two Weekeroo Station inclusions. These are not isochron ages, but rather assume that the initial $\mathrm{Sm} / \mathrm{Nd}$ elemental ratio up until the dated event was equal to that of chondrites. (A somewhat younger Sm-Nd model age of $3.0 \mathrm{Gyr}$ was also reported for Watson, and a Sm-Nd model age of 4.27 was reported for Miles.) No evidence exists in the derived Ár$\mathrm{Ar}, \mathrm{I}-\mathrm{Xe}$, and Rb-Sr ages of Weekeroo Station for such a young Sm-Nd model age. Further, Snyder et al. (1998) find old $\mathrm{Rb}-\mathrm{Sr}$ model ages for the same samples. We have three reasons for suspecting that these young Sm-Nd model ages do not represent significant thermal events on the IIE parent body, but rather are consequences of the model assumptions. First, diffusion of +3 rare earth ions should be slower in comparison to $\mathrm{Sr}^{+2}$ and $\mathrm{Rb}^{+1}$ ions, and the $\mathrm{Sm}-\mathrm{Nd}$ chronometer generally is expected to be harder to reset than either the K-Ar or Rb-Sr chronometers (Bogard, 1995). Secondly, if we assume that a single event reset ages in Watson, Netschaëvo, and Kodaikanal (as suggested above), then three radiometric chronometers ( $\mathrm{K}-\mathrm{Ar}, \mathrm{Rb}-\mathrm{Sr}$, and $\mathrm{Pb}-\mathrm{Pb}$ ) give essentially the same age, an age significantly older than the Sm-Nd model age of Watson (Table 2). Thirdly, if the young Sm-Nd model ages are real, then each of these three meteorites was affected by a separate thermal event at a very different time, none of which affected other IIE meteorites. If the thermal event that caused resetting of Weekeroo Station's Sm-Nd chronometer also produced differentiation of the silicate, it is difficult to understand why the other chronometers were not also reset. On the other hand, if the thermal event which reset Sm-Nd was a 
modest one, silicate differentiation for Weekeroo Station must have occurred at an earlier time, and the assumption of a chondritic Sm/Nd ratio prior to the Sm-Nd model age might not be true.

\section{DISCUSSION}

\section{Formation Models for IIE Irons}

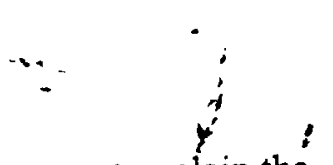

Any model which attempts to explain the petrology and chronology of IIE irons must explain the basic mechanism by which metal and silicates were mixed to produce the large-scale features observed in IIE meteorites (Fig. 1). Three general classes of models have been proposed. Wasserburg et al. (1968) first suggested that the silicate-bearing IIE Colomera formed through trapping of silicate melts in a small metallic melt pool which was itself enclosed in silicates. These authors rejected a shock origin. The generalized idea that silicate-bearing iron meteorites (e.g., LAB, IIE, and IIICD) and related stony meteorites (e.g., acapulcoites, lodranites, winonaites) formed through partial melting and incomplete differentiation of asteroids which were non-collisionally heated has been widely embraced (see Mittlefehldt et al., 1998 and references therein). In a different model, Wasson and Wang (1986) proposed that IIE iron meteorites formed in individual pools of impact-produced melt in the near-surface region of a chondritic parent body. In the view of Wasson and Wang (1986), melting of the Fe, Ni-FeS and basaltic components and their mixing occurred within these melt pools. This model was invoked by Olsen et al. (1994) to explain the origin of Watson. More recently, Casanova et al. (1995) have called both of these models into question. Casanova et al. (1995) rejected the impact hypothesis of Wasson and Wang (1986) on the lack of shock features they observed in a single silicate inclusion in Techado. Keil et al. (1997) marshaled evidence against impact as a heat source for any of the silicate-bearing irons or related stones. It is worth noting that the modeling of Keil et al. (1997) suggests that bodies would experience catastrophic fragmentation prior to significant heating. Such a conclusion may require revision in light of the presence of numerous craters on the intact asteroid Mathilde, which are greater than one-half the diameter of the asteroid. Casanova et al. (1995) also rejected the model of Wasserburg et al. (1968), since it did not readily explain mixing of chondritic, sometimes angular, inclusions into the metal, such as is seen in Netschaëvo and Techado. Instead, Casanova et al. (1995) invoked a new model in which non-collisional heating produced a range of silicate inclusion types that were collisionally mixed with the metal from the core of another asteroid, akin to models for mesosiderite formation. This hybrid model of non-collisional heating to form basic lithologies, followed by impact mixing to produce the meteorite, would seem capable of generating the broad array of features observed in silicate-bearing IIE irons, although we believe invoking two separate asteroids as sources of these lithologies is unnecessary. 
A related question in the case of the IIE irons is whether they originate from the same parent body as the H chondrites. This idea has been suggested by several authors (e.g., Casanova et al., 1995; Olsen et al., 1994) based on similarities in mineral compositions, oxygen isotopic compositions and some cosmic-ray exposure ages. The association of silicate-bearing IIE irons with the $\mathrm{H}$ chondrite parent body has been championed most recently by Gaffey and Gilbert (1998). We point out that several reasons exist to : doubt such a link. Mafic silicates in IIE irons exhibit a broad range of compositions from $\mathrm{Fa}_{14.1} \mathrm{Fs}_{13.8}$ in Netschaëvo to $F_{S_{23.5}}$ in Colomera (Bunch et al., 1970). In general, the differentiated silicate inclusions are richer in $\mathrm{FeO}$, consistent with enrichment of early partial melts in FeO. However, the most primitive silicate inclusions in IIE irons (Netschaëvo, $\mathrm{Fa}_{14.1}$; Techado, $\mathrm{Fa}_{16.4}$ ) exhibit olivine compositions outside the range typical for $\mathrm{H}$ chondrites $\left(\mathrm{Fa}_{16.9-20.4}\right.$; Gomes and $\left.\mathrm{Keil}, 1980\right)$. We fully recognize, however, that these silicate compositions could have been reduced during mixing and reaction with the metal. Further, the oxygen isotopic composition of silicate-bearing IIE irons $\left(\Delta^{17} \mathrm{O}=0.59 \pm 0.07\right.$; Clayton and Mayeda, 1996) differs slightly from that of equilibrated $\mathrm{H}$ chondrites $\left(\Delta^{17} \mathrm{O}=0.73 \pm 0.09\right.$; Clayton et al., 1991). Finally, although the space exposure ages of young IIEs Netschaëvo, Watson, and Kodaikanal are consistent with those of many H-chondrites, the exposure ages of Weekeroo Station, Miles, and Sombrerete are much older than any known H-chondrite. These observations suggest that, whereas the parent precursor to IIEs was very similar to $H$ chondrites, no convincing evidence exists that IIE irons and $\mathrm{H}$ chondrites come from the same parent body.

\section{Chronology Constraints on Formation}

The occurrence of both "old" and "young" meteorites within the IIE irons has important implications for their genesis. The compositional trends observed in the metallic portions of these meteorites (Wasson and Wang, 1986) is best explained by their formation on a single parent body. The simplest explanation for their origin would be that a single process produced the silicate/metal assemblages in all IIE irons. However, whereas those IIEs with older ages could have been formed by indigenous metamorphism within the parent body, we do not expect typical asteroids to sustain significant internal heat over times of $-0.8 \mathrm{Gyr}$. Thus, if the "young" radiometric ages of silicate represent the time of formation of these iron/silicate meteorites, then only impact-induced heating and mixing is a viable model. If non-collisional (i.e., internal) heating early in the history of the parent body produced these meteorites, then a different mechanism must be invoked to explain the "young" ages. The important chronological issue is whether the young IIE ages must represent formation of the metal/silicate assemblage or, altematively, age resetting by impact long after these meteorites formed. 
The radiometric chronology of silicates in those IIEs with old ages (Table 2) requires that at least some of these metal-silica:e assemblages formed relatively early in solar system histor:. For example, the oldest ages for Colomera and Sombrerete are within $-45 \mathrm{Myr}$ of the likely formation time of various meteorite parent bodies. The presence of a $l o w{ }^{182} \mathrm{~W} /{ }^{184} \mathrm{~W}$ ratio in Watson metal alsò argues for éarly separation of metal and siicate, prior to $\sim 4.5 \mathrm{Gyr}$ ago (Snyder et al., 1998). However, variations in : radiometric ages also suggest that final chronometer closure of the silicate in some IIE meteorites required a significant time period, $\sim 0.12 \mathrm{Gyr}$ in the case of Ar-Ar ages. The initial ${ }^{87} \mathrm{Sr} ;{ }^{36} \mathrm{Sr}$ values also imply a significant difference in $\mathrm{Rb}-\mathrm{Sr}$ closure times between Colomera and Weekeroo Station. These observations imply formation by an internal thermal process acting over time.

The most striking aspect of the isotopic chronology of IIE silicates is that three meteorites (Netschaëvo, Watson, and Kodaikanal) give relatively young radiometric ages of $\sim 3.67$ Gyr. These three also have the youngest space exposure ages and may have been ejected into space from a different part of the parent body. As with essentially all meteorites, there is no evidence that the impact events that initiated space exposure had any significant effect on the radiometric ages of any of the IIEs. It is much harder, however, to correlate petrologic features of IIE silicate with their radiometric age. For example, Netschaëvo, Techado, and Watson all have somewhat primitive, chondritic-like silicates. Netschaëvo compositionally resembles $\mathrm{H}$-chondrites and contains angular clasts showing minimum alteration; Techado was obviously heated to significant temperatures, but not differentiated; and Watson was heated sufficiently to segregate metal and sulfide from the silicate. However, the radiometric ages of Netschaëvo and Watson are young, whereas the Ar-Ar age of Techado is $\sim 4.49 \mathrm{Gyr}$, and certainly not as young as $3.67 \mathrm{Gyr}$. Silicates in the remaining IIEs show characteristics of being much more differentiated and processed. Whereas three of these more differentiated meteorites give relatively old radiometric ages, Kodaikanal silicate definitely gives a much younger age. The close similarity and likely identity of radiomerric ages for Kodaikanal, Netschaëvo, and Watson suggests that these ages were determined by a single process or event operating over a limited period of time, an event that did not affect the other IIEs. The issue is whether that process was the same or different from the process that formed the older IIEs.

Shock reheating may have reset at least the Ar-Ar ages of silicate inclusions in those IIE meteorites with "young" ages. In this work, we have documented extensive shock features in the silicates of some IIEs. The "differentiated" silicate inclusions in Colomera, Weekeroo Station, Miles, Kodaikanal and Elga all exhibit evidence of extensive post-solidification shock and associated post-shock temperature increases of up to $-300^{\circ} \mathrm{C}$. Osadchii et al. (1981) has argued that the radiating corona structures observed in these meteorites reflect shock remelting. We agree with this conclusion. Perhaps the most 
compelling argument for a shock origin for these features is the coexistence over scales of a centimeter of coarse-grained inclusions \pm fine-grained. radiating inclusions \pm glassy inclusions in meteorites such as Miles and Colomera (Ikeda and Prinz, 1996; Buchwald, 1975; this work). These textures require different cooling rates, which we interpret as a slow, early cooling during formation aind a rapid, postshock cooling history. The "primitive" inclusions in Netschaëvo, Techado and Watson are less"shockéd, but still exhibit shóck features corresponding to post-shock temperature increases of $\sim 100-150^{\circ} \mathrm{C}$. Olsen et al. (1994) documented that shock effects can be extremely heterogeneous. Further, shock effects are often the most severe within the silicatè inclusions, probably owing to their different compressibility relative to the metallic host. Thus, it would appear that individual silicate inclusions could have had drastically different shock and thermal histories.

It remains unclear, however, to what extent individual inclusions and isotopic chronometers might have been altered by shock. Resetting of Ar-Ar ages by impact heating often occurs in meteorites, but $\mathrm{Rb}-\mathrm{Sr}, \mathrm{Pb}-\mathrm{Pb}$, and $\mathrm{Sm}-\mathrm{Nd}$ ages are not as easily reset (Bogard, 1995; Shih et al., 1994). Impact heating may have been sufficient to reset $\mathrm{Pb}-\mathrm{Pb}$ and $\mathrm{Rb}-\mathrm{Sr}$ in Kodaikanal, which is the most extensively shocked of the silicate-bearing IIE irons. However, Burnett and Wasserburg (1967a) concluded that the Rb-Sr system in Kodaikanal could not have been reset at $\sim 3.7 \mathrm{Gyr}$ by simple homogenization of $\mathrm{Sr}$ isotopes, but rather that chemical fractionation and physical separation must have occurred near this time. The initial ${ }^{87} \mathrm{Sr} /{ }^{86} \mathrm{Sr}$ ratio at the time of the dated event was not well-defined. Even so, Kodaikanal $\mathrm{Rb} / \mathrm{Sr}$ could have evolved between $\sim 4.5$ and $\sim 3.7 \mathrm{Gyr}$ ago in a chondrite-like system, but it could not have evolved over this time period with the $\mathrm{Rb} / \mathrm{Sr}$ ratio measured in one of the inclusions (Burnett and Wasserburg, 1967a). It is not clear if impact heating could produce the differentiation and material interchange among different silicate inclusions within Kodaikanal that these data would require (e.g., Keil et al., 1997). It also is not clear that such metal-silicate mixing could occur without remelting both silicate and metal. If melting, differentiation, and chemical fractionation did occur during an impact event 3.67 Gyr ago, this event would represent the formation of Kodaikanal, and would violate any simple assumption that all IIE meteorites were formed by the same, early process.

The Rb-Sr, Sm-Nd, and $\mathrm{Pb}-\mathrm{Pb}$ systematics, including the ${ }^{87} \mathrm{Sr} /{ }^{86} \mathrm{Sr}$ and ${ }^{143} \mathrm{Nd} /{ }^{144} \mathrm{Nd}$ initial ratios, for the "primitive" inclusions in Netschaëvo and Watson have not been determined, so we do not know if these chronometers also indicate a young age for these meteorites. The primitive and undifferentiated nature of Netschaëvo silicate requires that it formed early. This characteristic suggests that radiometric ages other than Ar-Ar may not have been extensively reset. On the other hand, Netschaëvo did not give an ${ }^{129} \mathrm{I}-{ }^{129} \mathrm{Xe}$ correlation (Niemeyer, 1980). A single Rb-Sr analysis of Watson silicate (Snyder et al., 1998) plots close to the array defined by the Weekeroo Station $\mathrm{Rb}-\mathrm{Sr}$ data (Burnett and Wasserburg, 
1967b). However, this does not rule out impact resening of Rb-Sr. In addition, the isotopic composition of tungsten in Watson metal and silicate are not the same (Snyder et al., 1998), indicating that the metal and silicate were not in isotopic equilibrium after the decay of ${ }^{182} \mathrm{Hf}\left(\mathrm{T} / 2=9 \mathrm{Myr}\right.$ ). The ${ }^{182} \mathrm{~W} /{ }^{184} \mathrm{~W}$ ratio in Watson metal has a small negative anomaly, similar to that of other iron meteorites, but this ratio in Watson silicate does not show the higher anomaly found in some differentiated stony meteorites. Snyder et al. (1998) suggest that this difference is evidence that Watson metal and silicate derived from separate parent jodies. However, the data might also be explained if Watson silicate was not separated from metal until after ${ }^{182} \mathrm{Hf}$ decayed, and the silicate was later mixed with other metal that last equilibrated with siicate prior to ${ }^{182} \mathrm{Hf}$ decay.

\section{CONCLLSIONS}

We suggest that silicate differentiation and mixing with metal to form those IIE meteorites with highly differentiated silicates can be explained by variable degrees of metamorphism and melting caused by indigenous heat produced within an $\mathrm{H}$ chondrite-like parent body shortly after its formation. In such a process. an $\mathrm{Fe}, \mathrm{Ni}$-FeS melt forms first between 950 and $1000^{\circ} \mathrm{C}$, followed by a feldspar-enriched basaltic-like melt at temperatures in excess of $1050^{\circ} \mathrm{C}$. Migration of these melts due to thermal gradients deep within the parent body could produce a mixture of metal and basaltic silicates, leaving ultramafic olivine-pyroxene rocks as residues. Clearly, a broad range of differentiation occurred throughout the IIE parent body. Differentiation proceeded to a significant degree in some parts of the body and resulted in large masses of metal and highly differentiated silicate, whereas silicate in other parts of the body was unaltered. The tendency for silicate in the more differentiated IIEs to consist of small globular inclusions suggests that these silicates were plastic or molten when mixed with metal, which probably also was molten. This seems consistent with formation of these more differentiated meteorites in parts of the body which were hotter and experienced higher degrees of silicate differentiation. This differentiation and mixing of metal and silicate in IIEs with older ages must have occurred relatively soon after the parent body formed. The apparent range in ages among some differentiated Iles may have been produced either by an extended period in which differentiation of the silicate and mixing of this silicate with metal occurred, or by relatively slow cooling after this mixing.

Our preferred formation mechanism described above for those IIEs with highly differentiated silicates also may have occurred on some other parent bodies. A similar process has been inferred to explain the coexistence of metal with both mafic and basaltic silicate in the Caddo County IAB iron meteorite (Takeda et al., 1999). An analogous process may have formed primitive achondrites like winonaites and lodranites, which are believed to have been derived by partial melting and varying 
degrees of silicate and metal differentiation within parent bodies resembling H-chondrites (McCoy et al., 1997: Benedix et al., 1998). The parent bodies of winonaites and IAB irons may have been the same (Benedix et al.. 1998).

Available data do not uniquely define a specific model for the origin of those IIE meteorites with undifferentiated silicate. In principle. wo different explanations are possible. The first is that metalsilicate mixture for all IIEs formed early. and the young radiometric ages for Netschaëvo, Watson and Kodaikanal were reset by impact long after formation. The second explanation is that the metal-silicate mixing of the young IIEs occurred 3.67 Gyr ago, and of necessity was caused by large-scale impact. An issue relating to this second explanation is whether the metal would have to be melted and the silicate differentiated at the time of formation. or whether the mixing could be accomplished in the solid state. Existence of still-primitive silicate within Netschaëvo and Techado demonstrates that silicate-metal mixing occurred in these meteorites without causing appreciable differentiation of the silicate.

Presumably at the time of mixing, these silicates were relatively cold and the metal relatively hot, and the mixed assemblage cooled quickly. This suggests that silicate in these two meteorites originated from a much cooler region of the parent body, in comparison to the more differentiated IIEs, including Kodaikanal. Residual heat from the hot metal may have produced the recrystallized texture observed in the small Techado silicate inclusion described by Casanova et al. (1995). These characteristics suggest impact as the mixing process for formation of Techado and Netschaëvo.

No measured cinaracteristic of Netschaëvo and Watson seems to require that the silicate/metal assemblage of these two meteorites formed significantly later than $\sim 4.5 \mathrm{Gyr}$ ago The silicate and metal could have derived from the same parent body and could have been brought into association by a large impact -4.5 Gyr ago that excavated deeply. The reset Ar-Ar ages of Netschaëvo and Watson may have been produced by moderate shock heating at $3.67 \mathrm{Gyr}$, long after the silicate-metal mixtures formed. The unaltered nature of the silicate in Netschaëvo indicates that the impact event did not produce silicate melting and may not have reset the Rb-Sr and Sm-Nd chronometers. (It would be informative to determine $\mathrm{Rb}-\mathrm{Sr}$ and $\mathrm{Sm}-\mathrm{Nd}$ isochron ages of Netschaëvo and Watson silicate, to see if any significant evidence of resetting exists. Such a study should also include petrography to document the possible effects of shock reheating.) In contrast to this model, Casanova et al. (1995) concluded that impact mixing involved silicates from one parent body with a metal core from a different parent body.

Formation of Kodaikanal presents the greatest challenge in explaining the origin and chronology of IIEs. The close similarity in radiometric ages among Kodaikanal, Netschaëvo and Watson suggests resetting by the same impact event. However, both extensive resetting of radiometric ages and silicate fractionation obviously occurred in Kodaikanal, and it is not obvious that these changes could have been 
accomplished without appreciable melting of both silicate and metal 3.67 Gyr ago. Thus, separate mechanisms may have produced the differentiated silicate in Kodaikanal compared to other strongly differentiated IIEs. In spite of arguments that have been presented against impact-produced • ; differentiation (Keil et ai., 1997), we may have to reevaluate the ability of a large impact to produce widespread melting and differentiation in meteorites. If this is indeed the case, the situation may exist that similar mixtures of strongly differentiated silicate and metal were produced in the same parent body at different times by completely different mechanisms. The $3.67 \mathrm{Gyr}$ age of this impact event falls within a period of time when the moon was being impacted with large objects producing major basins and when the parent body of eucrites (Vesta?) was also experiencing impacts of sufficient size to reset Ar-Ar ages (Bogard, 1995).

Acknowledgments - We thank A. Brearley (Univ. of New Mexico), K. Keil (Univ. of Hawaii), R.S. Clarke, Jr. and G.J. MacPherson (Smithsonian Institution), G.J. Wasserburg (California Inst. of Technology) and J. Shwade for kindly providing samples for this study. Expert technical assistance from V. Yang and T. Servilla is appreciated. This manuscript has benefited substantially from helpful discussions with I. Casanova. This work was supported by NASA grant NAG 5-4490 (TJM) and RTOP 344-31-30-05 (DDB). 


\section{REFERENCES}

Alexander E.C. and Davis P.K. (1974) ${ }^{40} \mathrm{Ar}-{ }^{39} \mathrm{Ar}$ ages and trace element contents of Apollo 14 breccias: An interlaboratory cross-calibration of ${ }^{40} \mathrm{Ar}-{ }^{39} \mathrm{Ar}$ standards. Geochim. Cosmochim. Acta 38; 911-928.

Bence A.E. and Burnett B.S. (1969) Chemistry and mineralogy of the silicates and metal of the Kodaikanal meteorite. Geochim. Cosmochim. Acta 33, 387-407.

Benedix G.K., McCoy T.J., Keil K., Bogard D.D., and Garrison D.H. (1998) A petrologic and isotopic study of winonaites: Evidence for early partial melting, brecciation, and metamorphism. Geochim. Cosmochim. Acta 62, 2535-2553.

Bild R.W. and Wasson J.T. (1977) Netschaëvo: A new class of chondritic meteorite. Science 197, 5862.

Birck J.L. and Allègre C.J. (1978) Chronology and chemical history of the parent body of basaltic achondrites studied by the ${ }^{87} \mathrm{Rb} /{ }^{87} \mathrm{Sr}$ method. Earth Planet. Sci. Lett. 39, 37-51.

Birck J.L. and Allègre C.J. (1998) ${ }^{187}$ Re- ${ }^{187}$ Os in iron meteorites and the strange origin of the Kodaikanal meteorite. Meteorit. Planet. Sci. 33, 647-653.

Bogard D.D. (1995) Impact ages of meteorites: A synthesis. Meteoritics 30, 244-268.

Bogard D.D. and Cressy P.J. (1973) The production rates of $3 \mathrm{He}, 21 \mathrm{Ne}$, and 38Ar from target elements in the Bruderheim chondrite. Geochim Cosmochim Acta 37, 527-546.

Bogard D.D. and Garrison D.H. (1998) 39Ar-40Ar ages and thermal history of mesosiderites. Geochim Cosmochim Acta 62, 1459-1468.

Bogard D.D. and Garrison D.H. (1999) 39Ar-40Ar dating of thermal events on meteorite parent bodies. Lunar Planet. Sci. XXX,\#1104.

Bogard D.D, Burnett D.S., Eberhardt P., and Wasserburg G.J. (1968) ${ }^{40} \mathrm{Ar}-{ }^{40} \mathrm{~K}$ ages of silicate inclusions in iron meteorites. Earth Planet. Sci. Lett. 3, 275-283.

Bogard D.D, Burnett D.S., and Wasserburg G.J. (1969) Cosmogenic rare gases and the 40K-40Ar age of the Kodaikanal iron meteorite. Earth Planet. Sci. Lett. 5, 273-281.

Bogard D.D., Huneke J.C., Burnett D.S., and Wasserburg G.J. (1971a) Xe and Kr analyses of silicate inclusions from iron meteorites. Geochim Cosmochim Acta 35, 1231-1254.

Bogard D.D., Funkhouser J.G., Schaeffer O.A., and Zähringer (1971b) Noble gas abundances in lunar material - cosmic-ray spallation products and radiation ages from the Sea of Tranquility and the Ocean of Storms. J. Geophys. Res. 76, 2757-2779.

Brazzle R.H., Pravdivtseva O.V., Meshik A.P., and Hohenberg C.M. (1999) Verification and interpretation of the I-Xe chronometer, Geochim Cosmochim Acta 63, 739-760. 
Buchwald V.F. (1975) Handbook of Iron Meteorites. Univ. of California Press.

Bunch T.E. and Olsen E. (1968) Potassium feldspar in Weekeroo Station, Kodaikanal, and Colomera

iron meteorites. Science 160, 1223-1225.
Bunch T.E., Keil K. and Olsen E. (1970) Mineralogy and petrology of silicate inclusions in irori meteorites. Contrib. Min. Petrol. 25, 297-240.

Burnett D.S. and Wasserburg G.J. (1967a) Evidence for the formation of an iron meteorite at $3.8 \times 109$ years. Earth Planet. Sci. Lett. 2, 137-147.

Burnett D.S. and Wasserburg G.J. (1967b) ${ }^{87} \mathrm{Rb}-{ }^{87} \mathrm{Sr}$ ages of silicate inclusions in iron meteorites. Earth Planet Sci. Lett. 2, 397-408.

Casanova I., Graf T., and Marti K. (1995) Discovery of an unmelted H-chondrite inclusion in an iron meteorite. Science 268, 540-542.

Chen J.H. and Wasserburg G.J. (1985) U-Th-Pb isotopic studies on meteorite ALHA81005 and Ibitira. Lunar Planet. Sci. XVI, 119-120.

Clayton R.N., Mayeda T.K., Goswami J.N. and Olsen E.J. (1991) Oxygen isotope studies of ordinary chondrites. Geochim. Cosmochim. Acta 55, 2317-2337.

Clayton R.N. and Mayeda T.K. (1996) Oxygen isotope studies of achondrites. Geochim. Cosmochim. Acta 60, 1999-2017.

Evensen N.M., Hamilton P.J., Harlow G.E., Klimentidis R., O'Nions R.K. and Prinz M. (1979) Silicate inclusions in Weekeroo Station: Planetary differentiates in an iron meteorite (abstr.). LPSC X, 376378.

Eugster O. and Michel T. (1995) Common asteroid break-up events of eucrites, diogenites, and howardites and cosmic-ray production rates for noble gases in achondrites. Geochim Cosmochim Acta 59, 177-199.

Eugster O. (1988) Cosmic-ray production rates for ${ }^{3} \mathrm{He},{ }^{2 !} \mathrm{Ne},{ }^{38} \mathrm{Ar},{ }^{83} \mathrm{Kr}$, and ${ }^{126} \mathrm{Xe}$ in chondrites based on ${ }^{81} \mathrm{Kr}-\mathrm{Kr}$ exposure ages. Geochim Cosmochim Acta 52, 1649-1662.

Freundel M., Schultz L., and Reedy R.C. (1986) Terrestrial ${ }^{81} \mathrm{Kr}-\mathrm{Kr}$ ages of Antarctic meteorites. Geochim Cosmochim Acta 50, 2663-2673.

Gaffey M.J. and Gilbert S.L. (1998) Asteroid 6 Hebe: The probable parent body of the H-type ordinary chondrites and the IIE iron meteorites. Meteorit. Planet. Sci. 33, 1281-1295.

Garrison D.H. and Bogard D.D. (1998) Isotopic composition of trapped and cosmogenic noble gases in several Martian meteorites. Meteorit. Planet. Sci. 33, 721-736. 
Garrison D.H., Bogard D.D.. Albrecht A.A., Vogt S., Herzog G.F., Klein J., Fink D., DezfoulyArjomandy B., and Middleton R. (1992) Cosmogenic nuclides in core samples of the Chico L6 chondrite: Evidence for irradiation under high shielding. Meteoritics 27, 371-381:

Gomes C.B. and Keil K. (1980) Brazilian Stone Meteorites. Univ. of New Mexico Press, 161 . Göpel C., Manhès G., and Allègre C.J. (1985) Concordant 3,676 Myr U-Pb formation age for the Kodaikanal ịcormeteorite. Nature 317, 341-344.

Graf T. and Marti K. (1995) Collisional history of H chondrites. J. Geophys. Res. 100, 21,247-21,263.

Graf T., Baur H., and Signer P. (1990) A model for the production of cosmogenic nuclides in chondrites. Geochim Cosmochim Acta 54, 2521-2534.

Herpfer M.A., Larimer J.W., and Goldstein J.I. (1994) A comparison of metallographic cooling rate methods used in meteorites. Geochim Cosmochim Acta 58, 1353-1366.

Hohenberg C.M., Marti K., Podosek F.A., Reedy R.C., and Shirck J.R. (1978) Comparisons between observed and predicted cosmogenic noble gases in lunar samples. Proc. Lunar planet. Sci. Conf. $9^{\text {th }}$., 2311-2344.

Hohenberg C.M., Hudson B., Kennedy B.M., and Podosek F.A. (1981) Noble gas retention chronologies for the St Sèverin meteorite. Geochim Cosmochim Acta 45, 535-546.

Ikeda Y. and Prinz M. (1996) Petrology of silicate inclusions in the Miles IIE iron. Proc. NIPR Symp. Antarct. Meteorites 9, 143-173.

Ikeda Y., Yamamoto T., Kojima H., Imae N., Kong P., Ebihara M. and Prinz M. (1997a) Yamato791093, a metal-sulfide-enriched H-group chondritic meteorite transitional to primitive IIE irons with silicate inclusions. Antarct. Meteorite Res. 10, 335-353.

Ikeda Y., Ebihara M. and Prinz M. (1997b) Petrology and chemistry of the Miles IIE iron. I: Description and petrology of twenty new silicate inclusions. Antarctic. Meteorite Res. 10, 355-372.

Jentsch O. and Schultz L. (1996) Cosmogenic noble gases in silicate inclusions of iron meteorites: Effects of bulk composition on elemental production rates. J. Royal Soc. West. Australia 79, 67-71. Keil K., Stöffler D., Love S.G. and Scott E.R.D. (1997) Constraints on the role of impact heating and melting in asteroids. Meteoritics Planet. Sci. 32, 349-363.

Malvin D.J., Wang D. and Wasson J.T. (1984) Chemical classification of iron meteorites - X. Multielement studies of 43 irons, resolution of group IIIE from IIIAB, and evaluation of $\mathrm{Cu}$ as a taxonomic parameter. Geochim. Cosmochim. Acta 48, 785-804.

Manhes G., Göpel C., and Allègre C.J. (1987) High resolution chronology of the early solar system based on lead isotopes (abstr.). . Heteoritrics 22, 453-454. 
Table 3. Isotopic abundances (in units indicated of $\mathrm{cm}^{3} \mathrm{STP} / \mathrm{g}$ ) of $\mathrm{He}$, Ne, and $\mathrm{Ar}$ for $400^{\circ} \mathrm{C}$ and $1550^{\circ} \mathrm{C}$ extractions of unirradiated samples of IIE silicate. Calculated concentrations of cosmogences are estimatediat \pm are also given. Uncertainties are indicated below each isotopic ratio. Absolute abundances are estimatedat $5-10 \%$.

\begin{tabular}{|c|c|c|c|c|c|c|c|c|c|c|}
\hline $\begin{array}{c}\text { Sample } \\
{ }^{\circ} \mathrm{C} \\
\end{array}$ & $\begin{array}{c}{ }^{3} \mathrm{He} \\
10^{-8}\end{array}$ & $10^{-12} \mathrm{He}$ & $\begin{array}{l}-2 \mathrm{Ne} \\
10^{-8}\end{array}$ & $\begin{array}{l}31 \mathrm{Ne} e_{\mathrm{cos}} \\
10^{-8}\end{array}$ & ${ }^{20} \mathrm{Ne}^{22} \mathrm{Ne}$ & ${ }^{21} \mathrm{Ne} /{ }^{22} \mathrm{Ne}$ & $\begin{array}{l}{ }^{36} \mathrm{Ar} \\
10^{-8}\end{array}$ & ${ }_{10^{+5}}^{+5 \mathrm{Ar}}$ & ${ }_{10^{-8} \mathrm{Ar}_{\mathrm{cos}}}$ & ${ }^{38} \mathrm{Ar} /{ }^{36} \mathrm{Ar}$ \\
\hline \multicolumn{11}{|c|}{${ }^{\circ} \mathrm{C} \quad 10^{-8}$} \\
\hline 400 & 0.32 & 5.4 & 2.1 & 1.28 & $0.587+.025$ & $0.629+.002$ & 0.07 & 0.13 & 0.02 & $2.43+.21$ \\
\hline 1550 & 1.93 & 23.8 & 56.9 & 56.7 & $0.881+.001$ & $1.026+.001$ & 7.31 & 3.85 & 10.78 & $0.677+.001$ \\
\hline Total & 2.247 & 29.1 & 59.0 & 58.0 & & 1.012 & 7.38 & 3.98 & 10.8 & \\
\hline \multicolumn{11}{|c|}{$\begin{array}{l}\text { Total } 2.247 \\
\text { Netschaevo }\end{array}$} \\
\hline 400 & 0.02 & 0.29 & 0.02 & 0.02 & $2.029+.060$ & $0.880+.015$ & 0.05 & 0.03 & 0.06 & $0.876+.120$ \\
\hline 1550 & 0.94 & 0.79 & 0.98 & 0.96 & $0.866+.015$ & $1.011+.004$ & 0.41 & 1.13 & 0.10 & $2.445+.022$ \\
\hline Total & 0.96 & 1.08 & 1.00 & 0.98 & & 1.008 & 0.46 & 1.16 & 0.16 & \\
\hline \multicolumn{11}{|c|}{$\begin{array}{l}\text { Total } \quad 0.96 \\
\text { Sombrerete }\end{array}$} \\
\hline 400 & 9.1 & 1.9 & 0.1 & 0.1 & $0.836+.185$ & $0.735+.023$ & 0.34 & 0.1 & 0.31 & $1.013+.009$ \\
\hline 1550 & 276.1 & 39.8 & 59.2 & 57.4 & $0.866+.001$ & $1.000+.001$ & 54.3 & 16.5 & 61.0 & $0.855+.001$ \\
\hline Total & 285.2 & 41.7 & 59.3 & 57.5 & & 0.999 & 54.7 & 16.6 & 61.3 & \\
\hline \multicolumn{11}{|c|}{$\begin{array}{l}\text { Total } 285.2 \quad 41.7 \\
\text { Colomera feldspar }\end{array}$} \\
\hline 400 & 0.75 & 0.69 & 0.02 & 0.01 & $4.19+1.75$ & $0.425+.131$ & 0.3 & 2.26 & 0.18 & $1.405+.031$ \\
\hline 1550 & 12.23 & 7.82 & 7.93 & 7.54 & $0.886+.017$ & $0.980+.002$ & 25.85 & n.m. & 45.14 & $0.583+.001$ \\
\hline Total & 12.98 & 8.51 & 7.95 & 7.55 & & 0.979 & 26.15 & & 45.32 & \\
\hline
\end{tabular}


Table 4. Approximate Space Exposure Ages (Ma) of IIE Meteorites.

\begin{tabular}{lrrrl}
\hline Meteorite & ${ }^{3} \mathrm{He}$ & ${ }^{11} \mathrm{Ne}$ & ${ }^{38} \mathrm{Ar}$ & Reference \\
\hline Watson (s) & 8.2 & 8.5 & 7.9 & Olsen et al., 94 \\
Kodaikanal (m) & 12 & 15 & 15 & Bogard et al., 69 \\
Netschaëvo (s) & 0.6 & 3.0 & 3.6 & This study \\
& -- & -- & 18 & Niemeyer, 80 \\
Colomera (s) & 7 & 35 & $103 / 27$ & This study \\
Sombrerete (s) & 165 & 278 & $553 / 819$ & This study ${ }^{(a)}$ \\
Weekeroo Sta. (m) & 565 & 530 & 665 & Bogard et al., 69 \\
Weekeroo Sta. (s) & & & $350-410$ & Niemeyer, 80 \\
Miles (s) & 130 & 215 & $85 / 218$ & This study \\
Techado (s) & 64 & 56 & 27 & Casanova et al., 95 \\
Techado (m) & & & $60-80$ & Casanova et al., 95 \\
\hline
\end{tabular}

(s) silicate phase; (m) metal phase

(a) See text for discussion of Sombrerete ${ }^{38} \mathrm{Ar}$ age.

(b) Calculated using $\mathrm{H}$-chondrite production rates 
Table 5. Abundances of ${ }^{132} \mathrm{Xe}\left(10^{-12} \mathrm{~cm}^{2} \mathrm{STP} / \mathrm{g}\right)$ and relative $\mathrm{Xe}$ isotopic composition ( $\left.{ }^{132} \mathrm{Xe}=1.00\right)$ of IIE silicate. Two ${ }^{132} \mathrm{Xe}$ abundances are given for each sample. The first is the $400^{\circ} \mathrm{C}$ extraction, and the second is the melt extraction. Isotopic abundances are from the melt extraction, and the uncertainties for these are given below each isotope.

\begin{tabular}{ccccccccccc}
\hline & $\begin{array}{c}\text { i3fरe } \\
10^{-12} \text {,ce/g }\end{array}$ & $\begin{array}{c}136 \\
\pm\end{array}$ & $\begin{array}{c}134 \\
\pm\end{array}$ & $\begin{array}{c}131 \\
\pm\end{array}$ & $\begin{array}{c}130 \\
\pm\end{array}$ & $\begin{array}{c}129 \\
\pm\end{array}$ & $\begin{array}{c}128 \\
\pm\end{array}$ & $\begin{array}{c}126 \\
\pm\end{array}$ & $\begin{array}{c}124 \\
\pm\end{array}$ \\
\hline Sombrerete & 3.85 & 0.267 & 0.314 & $\equiv 1.0$ & 1.434 & 0.395 & 4.423 & 0.481 & 0.232 & 0.122 \\
& 164 & 0.013 & 0.005 & & 0.032 & 0.007 & 0.106 & 0.011 & 0.006 & 0.007 \\
Colomera & 28.4 & 0.273 & 0.392 & $\equiv 1.0$ & 1.238 & 0.295 & 2.011 & 0.357 & 0.179 & 0.086 \\
feldspar & 22.9 & 0.030 & 0.030 & & 0.093 & 0.023 & 0.122 & 0.027 & 0.012 & 0.018 \\
Miles & 4.12 & 0.323 & 0.387 & $\equiv 1.0$ & 1.203 & 0.207 & 1.092 & 0.241 & 0.107 & n.m. \\
& 76.7 & 0.035 & 0.054 & & 0.164 & 0.064 & 0.120 & 0.051 & 0.028 & \\
\multirow{2}{*}{ Netschaevo } & 17.3 & 0.319 & 0.376 & $\equiv 1.0$ & 0.843 & 0.171 & 1.123 & 0.083 & n.m. & n.m. \\
& 30.1 & 0.012 & 0.009 & & 0.021 & 0.010 & 0.033 & 0.005 & & \\
\hline
\end{tabular}



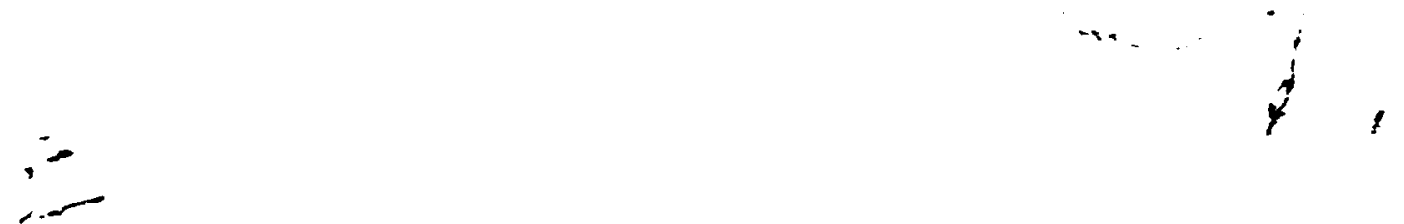

$\because \therefore$

$\because$ 


\section{FIGURE CAPTIONS}

Figure 1. Silicate inclusions in IIE iron meteorites. (a) Angular-silicate inclusions in Netschaëvo are chondrule-bearing and undifferentiated. Inclusion is $3 \mathrm{~cm}$ long at base. (b) A single silicate inclusion in Techado is undifferentiated, but the shape is suggestive of softening and stretching. Inclusionis $13 \mathrm{~mm}$ in maximum dimension. (c) The irregular inclusions in Watson are depleted in Fe, $\mathrm{Ni}$ metal and troilite. Inclusion is $25^{*}$ morm in length. (d) Globular. gabbroic inclusions such as these in Colomera are aiso found in Miles. Weekeroo Station, Kodaikanal and Elga. Width of field of view is $25 \mathrm{~mm}$.

Figure 2. Backscattered electron images of differentiated silicate inclusions in IIE irons. (a) Gabbroic inclusion in Miles composed of plagioclase (pl), augite (aug) and orthopyroxene (opx) in metal (m). Bright linear features in plagioclase are infilling of planar fractures produced by shock with terrestrial hydrated iron oxides. Scale bar $=500 \mu \mathrm{m}$. (b) Partially cryptocrystalline inclusion in Weekeroo Station with a large, euhedral central augite-orthopyroxene grain rimmed by a fine-grained radiating mass of pyroxene, plagioclase, $\mathrm{SiO} 2$ and chromite. Scale bar $=100 \mu \mathrm{m}$. (c) Inclusion in Colomera with glassy feldspathic groundmass (gl), skeletal phosphates (ph), and chromite (cr) in metal (m). Scale bar $=100 \mu \mathrm{m}$. The meniscus-shaped boundary between the feldspathic glass and phosphates has been suggested as evidence of liquid immiscibility (Buchwald, 1975).

Figure 3. ${ }^{39} \mathrm{Ar}-{ }^{40} \mathrm{Ar}$ ages (rectangles) and $\mathrm{K} / \mathrm{Ca}$ ratios (stepped line) as a function of cumulative release of ${ }^{39} \mathrm{Ar}$ for stepwise temperature extractions of silicate from the Watson IIE meteorites. Individual age uncertainties are indicated by the widths of the rectangles and include all analytical uncertainties, but not that associated with the age of the hornblende age monitor, estimated at $\pm 0.5 \%$.

Figure 4. ${ }^{39} \mathrm{Ar}-{ }^{40} \mathrm{Ar}$ ages (rectangles) and $\mathrm{K} / \mathrm{Ca}$ ratios (stepped line) as a function of cumulative release of ${ }^{39} \mathrm{Ar}$ for stepwise temperature extractions of IIE meteorites: (a) Techado, (b) Miles, (c) Colomera feldspar, and (d) Sombrerete. Individual age uncertainties are indicated by the widths of the rectangles and include all analytical uncertainties, but not that associated with the age of the hornblende age monitor, estimated at $\pm 0.5 \%$.

Figure 5. Comparison of relative isotopic concentrations of cosmogenic $\mathrm{Xe}$ in Sombrerete, Colomera feldspar, and Miles (this study); in Weekeroo Station (Bogard et al, 1968); and in the Stannem eucrite (Marti et al., 1966). A trapped Xe component with the composition of AVCC Xe has been subtracted, and the cosmogenic spectrum is normalized to ${ }^{126} \mathrm{Xe}=1$. Measurement uncertainties are smaller than the symbol except where indicated. 

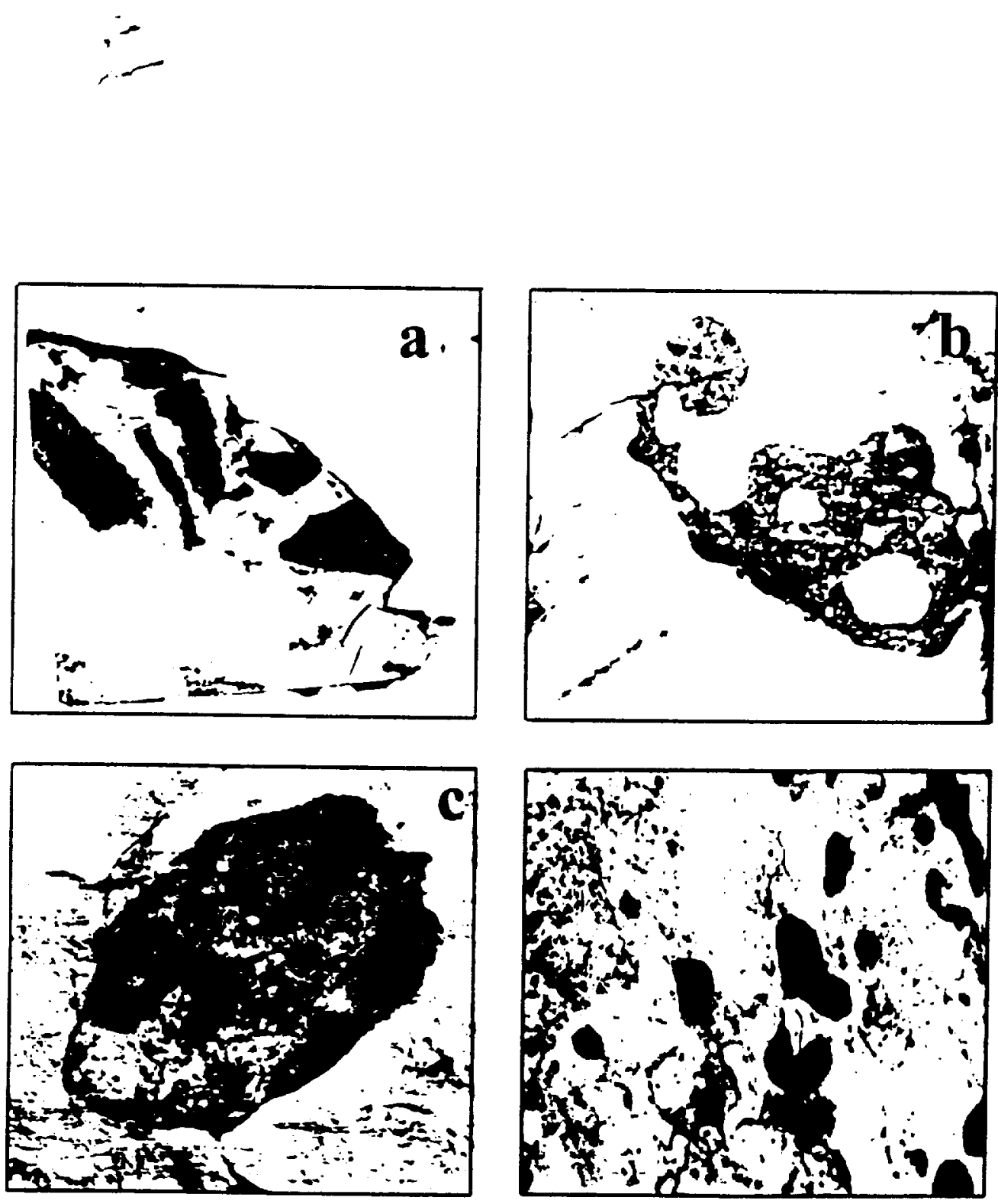


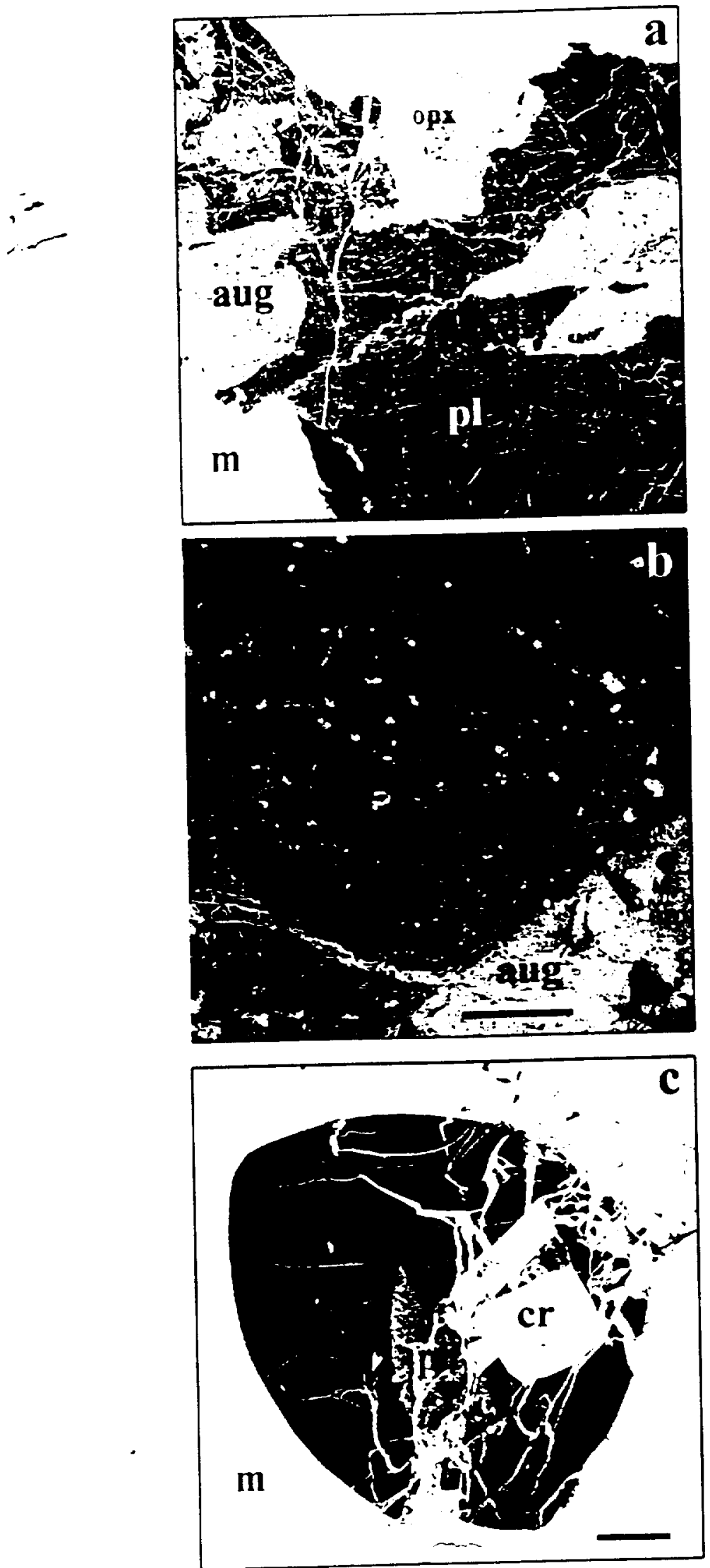




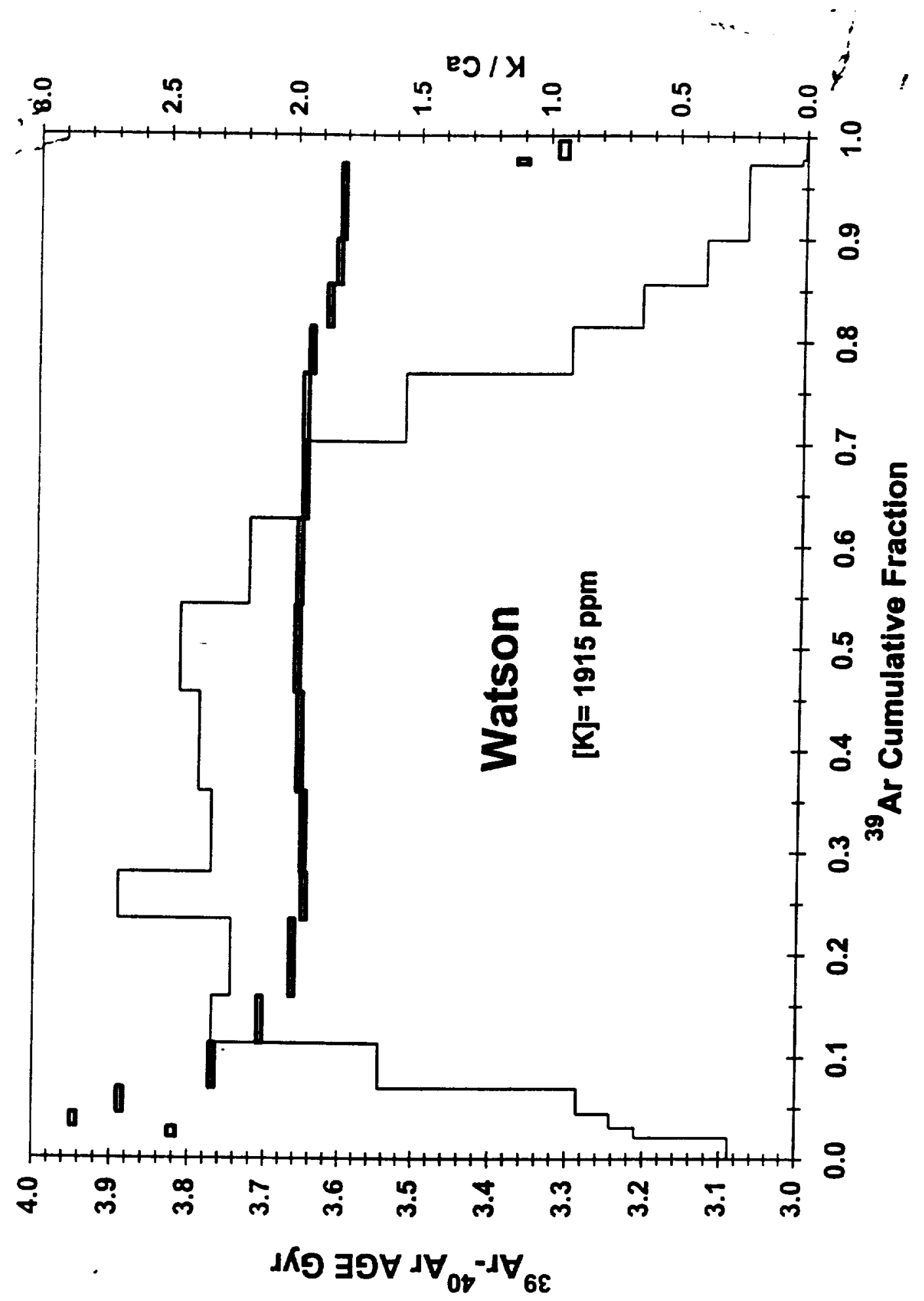




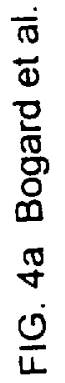

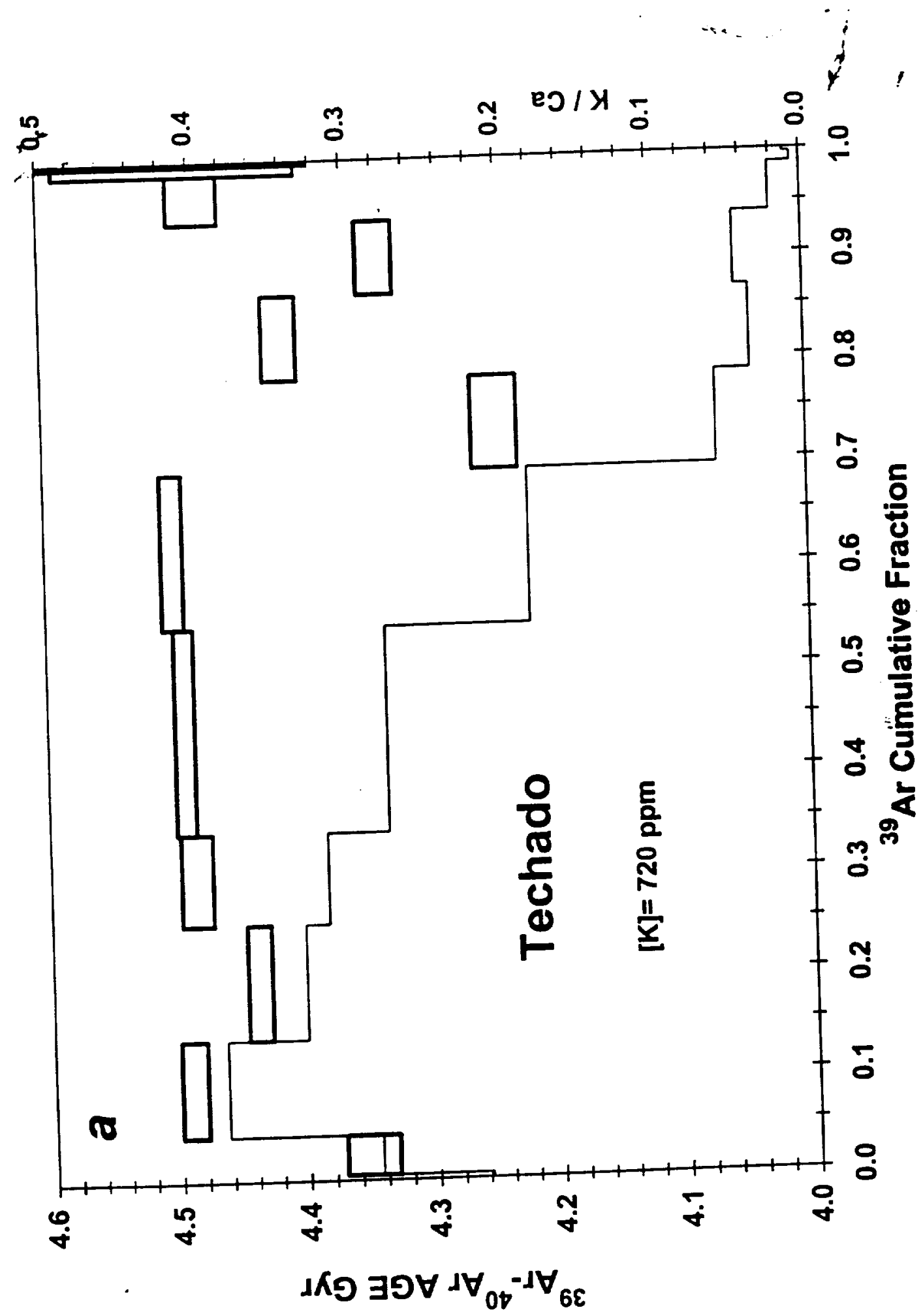




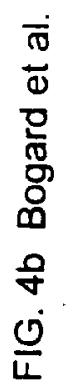

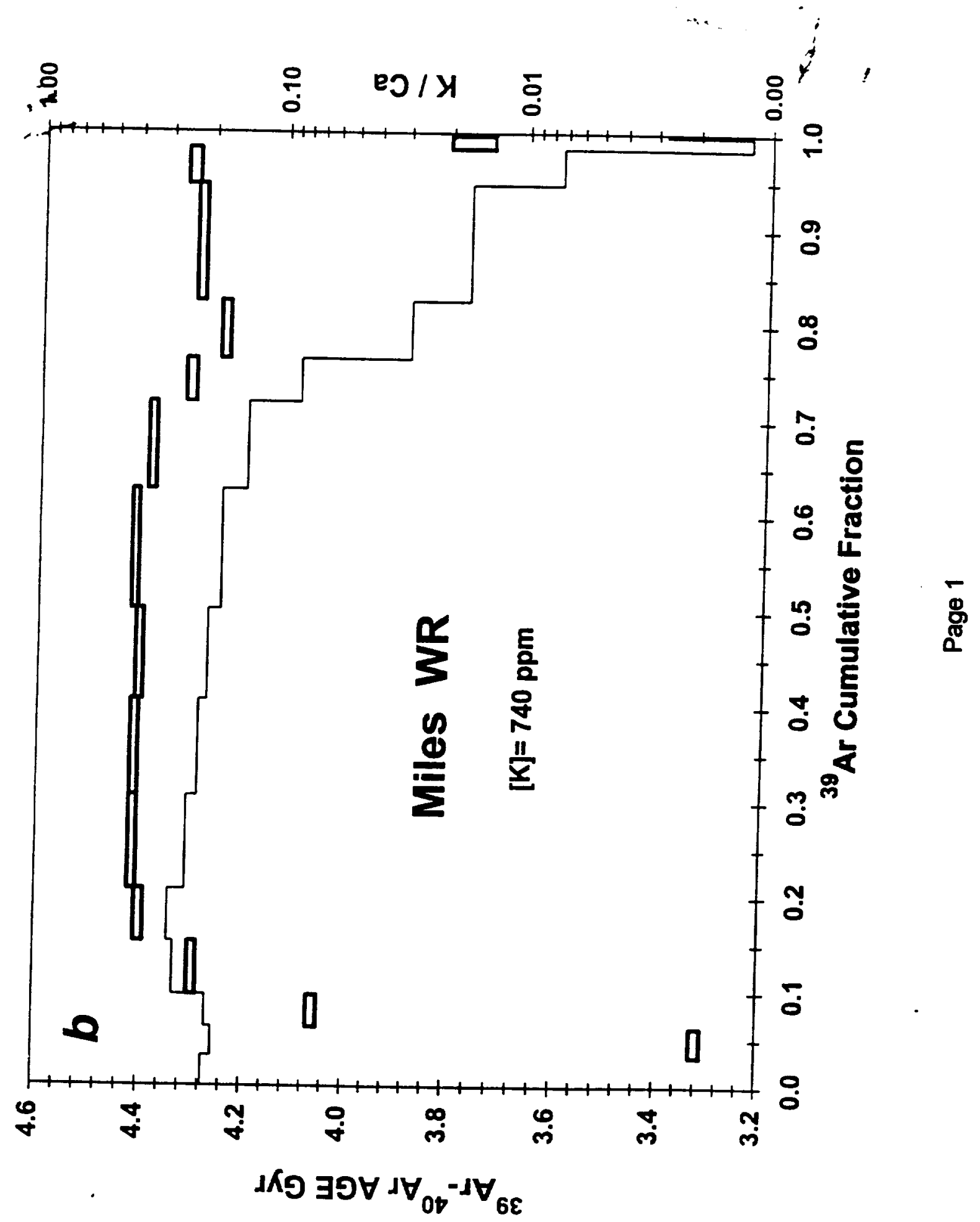




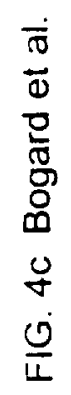

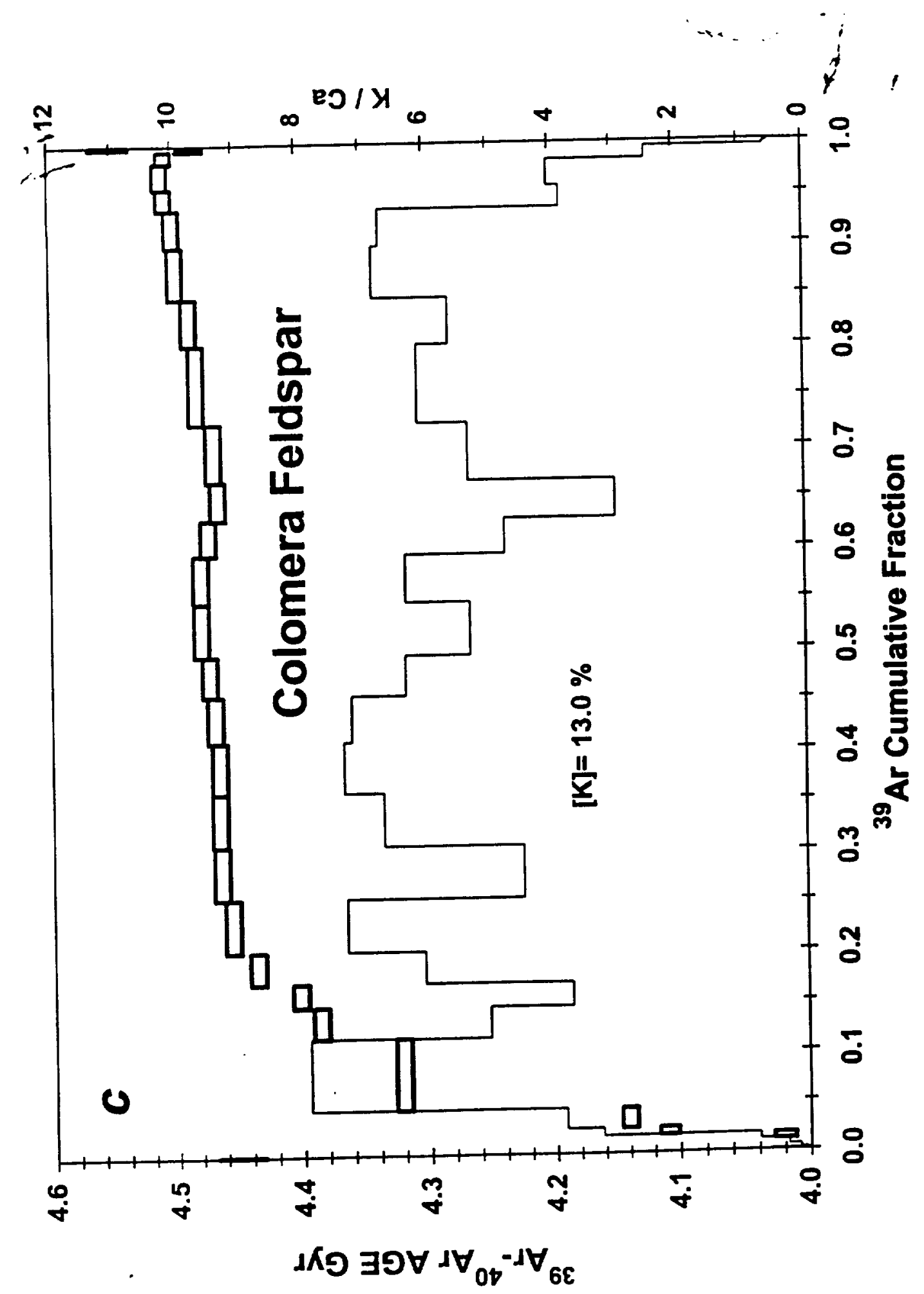




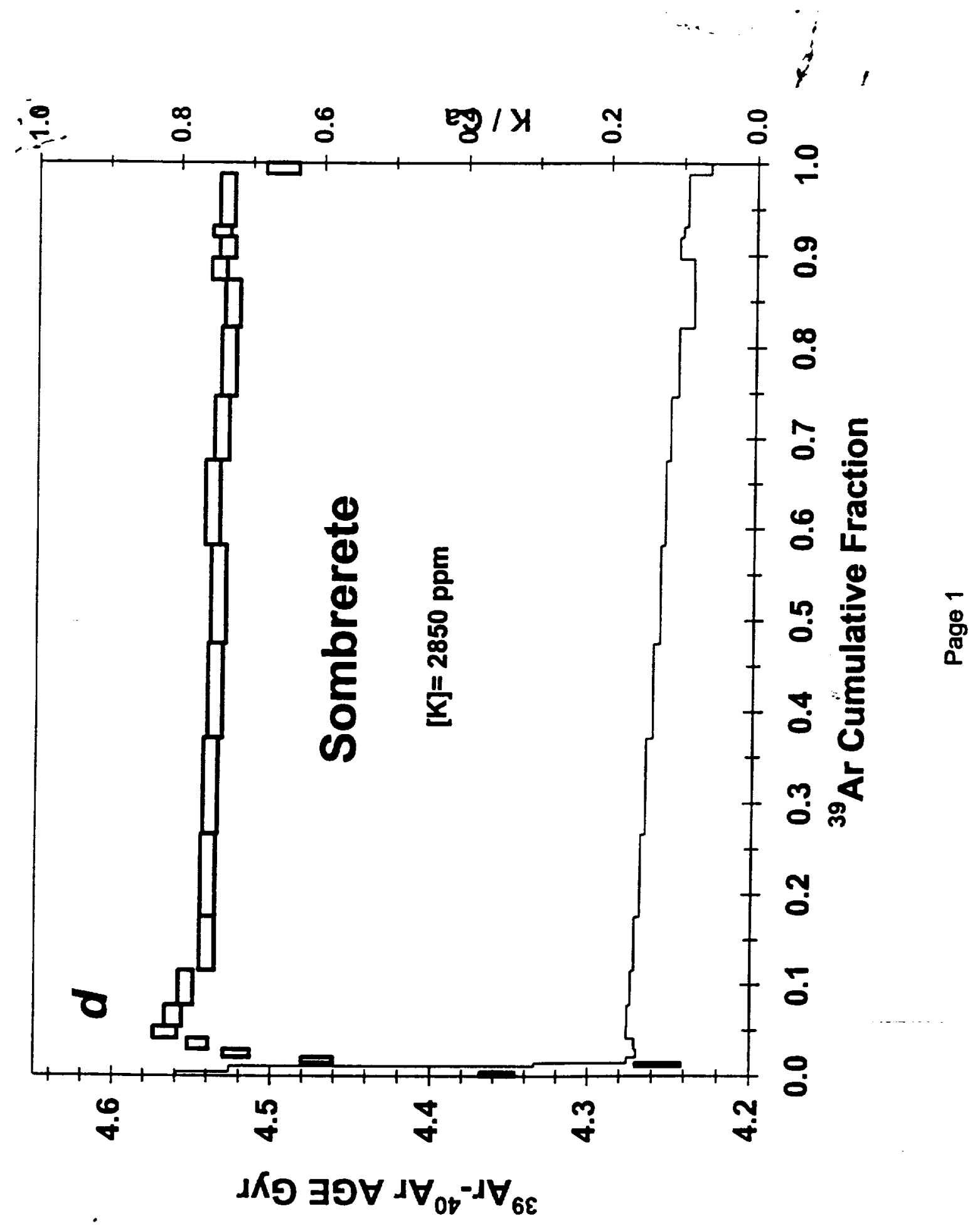


FIG. 5 Bojard ef al

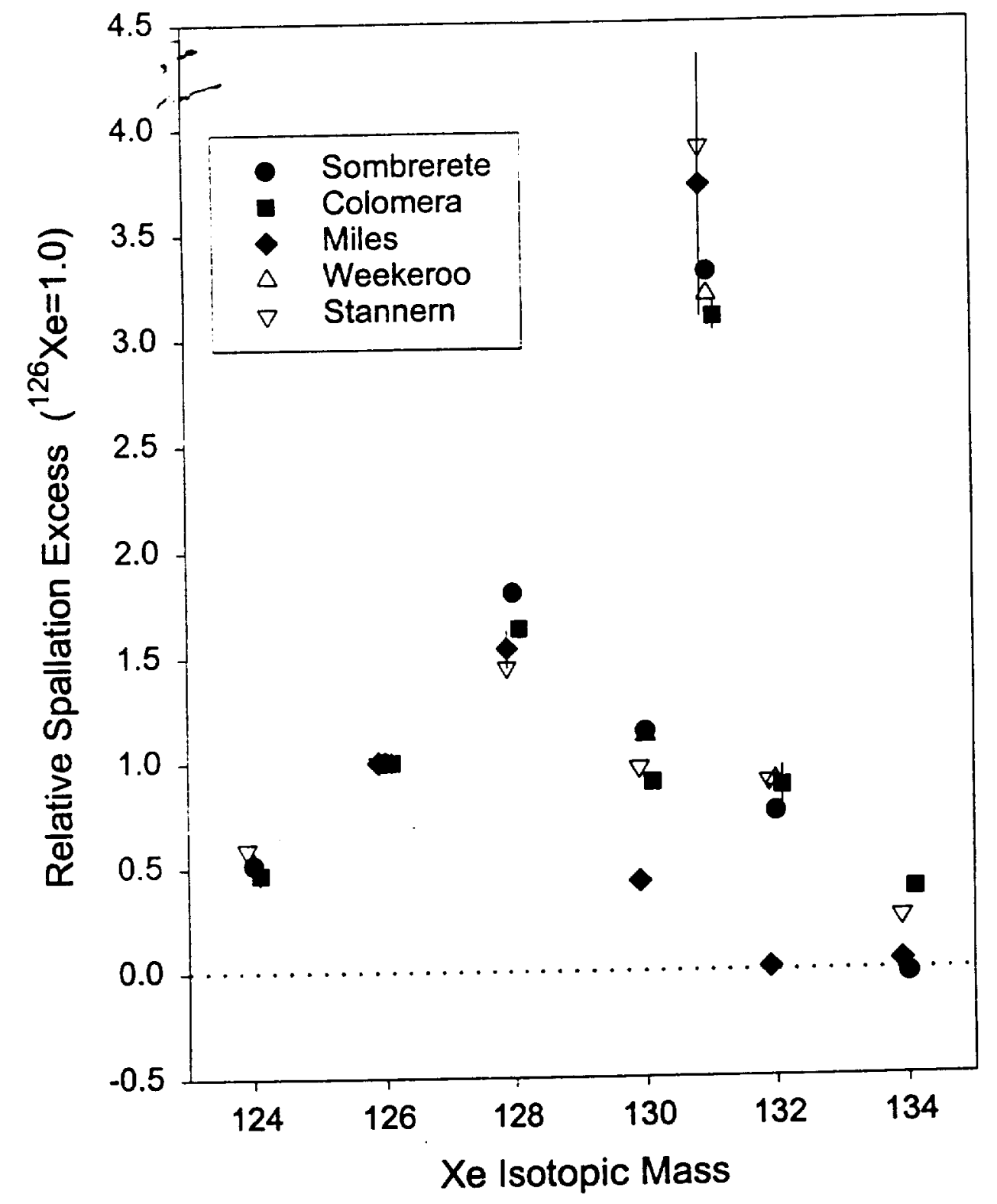




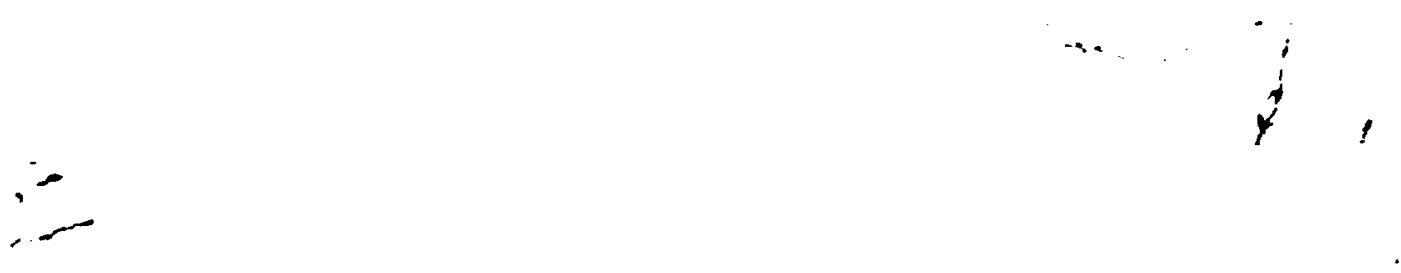

$\because \therefore$

$\because$ 
APPENDIX 1. Bogard et al.

\begin{tabular}{|c|c|c|c|c|c|c|c|}
\hline $\begin{array}{c}\text { Temp. } \\
\text { C }\end{array}$ & $\begin{array}{c}\text { 39Ar } \\
\text { ccSTP/g } \\
x \theta+8\end{array}$ & $\begin{array}{r}\text { AGE } \\
\text { Gyr } \\
+-\end{array}$ & $\begin{array}{l}\text { KICa } \\
X 100 \\
+- \\
\end{array}$ & $\begin{array}{r}40 / 39 \\
\quad \times 1 \\
+-\quad \\
\end{array}$ & $\begin{array}{r}38 / 39 \\
\times 100 \\
+. \\
\end{array}$ & $\begin{array}{c}37 / 39 \\
\times 100 \\
+- \\
\end{array}$ & $\begin{array}{l}36 / 39 \\
\times 1000 \\
+-\end{array}$ \\
\hline Watson & \multicolumn{2}{|c|}{$47.2 \mathrm{mg}$} & \multicolumn{2}{|c|}{$J=0.0980+-0.0002$} & & & \\
\hline \multirow[t]{2}{*}{400} & 2.628 & 2.657 & 26.60 & 34.31 & 189.39 & 206.80 & 5.48 \\
\hline & & 0.009 & 0.31 & 0.20 & 1.55 & 2.40 & 0.80 \\
\hline \multirow[t]{2}{*}{450} & 1.234 & 3.821 & 63.06 & 74.62 & 32.93 & 87.21 & 0.22 \\
\hline & & 0.005 & 0.65 & 0.18 & 0.21 & 0.90 & 0.24 \\
\hline \multirow[t]{2}{*}{500} & $1, \overline{7} \div 4$ & 3.945 & 72.95 & 80.69 & 12.95 & 75.39 & 0.05 \\
\hline & & 0.004 & 0.74 & 0.12 & 0.16 & 0.77 & 0.22 \\
\hline \multirow[t]{2}{*}{550} & 3.137 & 3.887 & 85.71 & 77.80 & 4.39 & 64.17 & 0.27 \\
\hline & & 0.004 & 0.86 & 0.08 & 0.13 & 0.65 & 0.15 \\
\hline \multirow[t]{2}{*}{600} & 5.573 & 3.769 & 163.66 & 72.22 & 1.69 & 33.60 & 0.15 \\
\hline & & 0.003 & 1.65 & 0.06 & 0.13 & 0.34 & 0.09 \\
\hline \multirow[t]{2}{*}{625} & 5.739 & 3.707 & 230.87 & 69.43 & 1.04 & 23.82 & 0.14 \\
\hline & & 0.003 & 2.33 & 0.05 & 0.13 & 0.24 & 0.09 \\
\hline \multirow[t]{2}{*}{650} & 9.551 & 3.663 & 223.65 & 67.54 & 1.20 & 24.59 & 0.21 \\
\hline & & 0.003 & 2.25 & 0.05 & 0.13 & 0.25 & 0.08 \\
\hline \multirow[t]{2}{*}{675} & 5.744 & 3.648 & 267.56 & 66.89 & 0.67 & 20.56 & 0.01 \\
\hline & & 0.003 & 2.70 & 0.05 & 0.13 & 0.21 & 0.06 \\
\hline \multirow[t]{2}{*}{725} & 10.132 & 3.650 & 231.71 & 66.97 & 0.73 & 23.74 & 0.03 \\
\hline & & 0.003 & 2.33 & 0.03 & 0.13 & 0.24 & 0.06 \\
\hline \multirow[t]{2}{*}{750} & 12.281 & 3.656 & 236.96 & 67.23 & 0.49 & 23.21 & 0.02 \\
\hline & & 0.004 & 2.39 & 0.07 & 0.13 & 0.23 & 0.05 \\
\hline \multirow[t]{2}{*}{775} & 10.902 & 3.661 & 244.76 & 67.42 & 0.32 & 22.47 & 0.15 \\
\hline & & 0.003 & 2.46 & 0.06 & 0.13 & 0.23 & 0.07 \\
\hline \multirow[t]{2}{*}{800} & 10.607 & 3.659 & 218.02 & 67.34 & 0.29 & 25.23 & 0.36 \\
\hline & & 0.003 & 2.19 & 0.06 & 0.13 & 0.25 & 0.10 \\
\hline \multirow[t]{2}{*}{825} & 9.557 & 3.653 & 197.38 & 67.09 & 0.28 & 27.86 & 0.02 \\
\hline & & 0.003 & 1.98 & 0.04 & 0.13 & 0.28 & 0.06 \\
\hline \multirow[t]{2}{*}{875} & 8.423 & 3.653 & 155.24 & 67.08 & 0.35 & 35.43 & 0.25 \\
\hline & & 0.003 & 1.56 & 0.06 & 0.1 & 0.36 & 0.10 \\
\hline \multirow[t]{2}{*}{910} & 5.770 & 3.645 & 90.88 & 66.77 & 0.60 & 60.52 & 0.03 \\
\hline & & 0.003 & 0.91 & 0.04 & 0.13 & 0.61 & 0.08 \\
\hline \multirow[t]{2}{*}{950} & 5.284 & 3.622 & 63.81 & 65.78 & 0.95 & 86.19 & 0.87 \\
\hline & & 0.004 & 0.64 & 0.06 & 0.13 & 0.87 & 0.14 \\
\hline \multirow[t]{2}{*}{1000} & 5.567 & 3.611 & 39.28 & 65.30 & 1.05 & 140.02 & 0.66 \\
\hline & & 0.004 & 0.39 & 0.06 & 0.13 & 1.41 & 0.21 \\
\hline \multirow[t]{2}{*}{1075} & 9.331 & 3.606 & 23.38 & 65.09 & 0.94 & 235.28 & 0.82 \\
\hline & & 0.003 & 0.23 & 0.05 & 0.13 & 2.36 & 0.20 \\
\hline \multirow[t]{2}{*}{1125} & 0.668 & 3.370 & 2.0 & 55.87 & 4.62 & 2705.1 & 6.55 \\
\hline & & 0.007 & 0.02 & 0.24 & 0.18 & 29.6 & 1.45 \\
\hline 1250 & 2.218 & 3.318 & 0.56 & 53.98 & 10.50 & 9890.1 & 35.84 \\
\hline & & 0.006 & 0.01 & 0.19 & 0.21 & 105.1 & 3.32 \\
\hline 1350 & 0.545 & 2.813 & 0.27 & 38.33 & 33.49 & 20750.8 & 111.78 \\
\hline & & 0.014 & 0.00 & 0.38 & 0.51 & 292.5 & 7.45 \\
\hline 1450 & 0.050 & 2.483 & 1.20 & 30.21 & 50.34 & 4593.0 & 238.84 \\
\hline & & 0.128 & 0.14 & 2.87 & 39.73 & 546.5 & 283.58 \\
\hline 1550 & 0.006 & 2.258 & 1.84 & 25.47 & 37.67 & 2982.9 & 127.56 \\
\hline & & 0.329 & 0.48 & 6.50 & 14.32 & 777.4 & 50.87 \\
\hline
\end{tabular}




\begin{tabular}{|c|c|c|c|c|c|c|c|}
\hline \multirow{3}{*}{$\begin{array}{c}\text { Techado } \\
400\end{array}$} & \multicolumn{2}{|c|}{$9.9 \mathrm{mg}$} & \multicolumn{2}{|c|}{$J=0.03002+-0.06010$} & \multirow[b]{2}{*}{33831} & \multirow[b]{2}{*}{255.63} & \multirow{2}{*}{417.44} \\
\hline & 0.070 & 3.737 & 21.52 & 231.09 & & & \\
\hline & & 0.107 & 1.51 & 15.71 & 53 & 17.98 & 78.32 \\
\hline \multirow[t]{2}{*}{550} & 0.571 & 4.351 & 28.69 & 338.31 & 95.46 & 191.73 & 9.68 \\
\hline & & 0.020 & 0.46 & 4.05 & 1.51 & 3.05 & 3.04 \\
\hline \multirow[t]{2}{*}{625} & 1.388 & 4.490 & 38.60 & 367.92 & 24.52 & 142.50 & 13.09 \\
\hline & & 0.010 & 0.44 & 1.89 & 0.38 & 1.62 & 2.77 \\
\hline \multirow[t]{2}{*}{675} & 1.653 & 4.436 & 33.29 & 356.15 & 23.05 & 165.21 & 16.52 \\
\hline & & 0.010 & 0.37 & 1.71 & 0.34 & 1.85 & 2.91 \\
\hline \multirow[t]{2}{*}{725} & 1.323 & 4.484 & 31.75 & 366.67 & 15.50 & 173.22 & 14.32 \\
\hline & & 0.012 & 0.39 & 2.44 & 0.39 & 2.10 & 3.08 \\
\hline \multirow[t]{2}{*}{800} & $2.923-$ & 4.491 & 27.76 & 368.25 & 13.24 & 198.10 & 22.94 \\
\hline & & 0.008 & 0.29 & 1.17 & 0.21 & 2.08 & 2.34 \\
\hline \multirow[t]{2}{*}{850} & 2.216 & 4.498 & 18.23 & 369.83 & 14.00 & 301.70 & 39.46 \\
\hline & & 0.008 & 0.20 & 1.42 & 0.26 & 3.24 & 3.34 \\
\hline \multirow[t]{2}{*}{900} & 1.322 & 4.244 & 5.79 & 316.87 & 25.70 & 949.22 & 116.66 \\
\hline & & 0.018 & 0.08 & 3.39 & 0.50 & 13.91 & 6.66 \\
\hline \multirow[t]{2}{*}{975} & 1.200 & 4.410 & 3.51 & 350.52 & 27.53 & 1567.09 & 136.39 \\
\hline & & 0.013 & 0.04 & 2.57 & 0.48 & 19.47 & 7.17 \\
\hline 1075 & 1.045 & 4.335 & 4.45 & 334.91 & 35.19 & 1237.14 & 170.34 \\
\hline & & 0.014 & 0.06 & 2.61 & 0.57 & 15.71 & 8.23 \\
\hline 1175 & 0.682 & 4.476 & 2.04 & 364.94 & 83.55 & 2697.6 & 612.6 \\
\hline & & 0.020 & 0.03 & 4.20 & 1.37 & 41.2 & 15.9 \\
\hline 1300 & 0.133 & 4.491 & 0.60 & 368.18 & 242.54 & 9173.6 & 2153.0 \\
\hline & & 0.096 & 0.04 & 21.33 & 17.39 & 541.7 & 165.6 \\
\hline 1550 & 0.057 & 4.798 & 1.05 & 442.72 & 504.00 & 5230.6 & 4077.9 \\
\hline & & 0.411 & 0.26 & 108.54 & 168.81 & 1294.5 & 1410.1 \\
\hline Miles & & $3 \mathrm{mg}$ & 0.03007 & -0.00011 & & & \\
\hline 400 & 0.479 & 1.467 & 20.05 & 41.74 & 67.36 & 274.33 & 73.87 \\
\hline & & 0.011 & & 0.41 & 0.96 & 3.89 & 5.94 \\
\hline 500 & 0.453 & 3.318 & 18.34 & 176.02 & 39.84 & 299.83 & 59.19 \\
\hline & & 0.010 & 0.21 & 1.00 & 0.46 & 3.46 & 6.12 \\
\hline 575 & 0.506 & 4.059 & 19.52 & 282.27 & 34.98 & 281.69 & 103.79 \\
\hline & & 0.010 & 0.22 & 1.42 & 0.39 & 3.17 & 5.41 \\
\hline 650 & 0.828 & 4.296 & 26.80 & 326.55 & 24.50 & 205.25 & 106.53 \\
\hline & & 0.008 & 0.29 & 1.16 & 0.28 & 2.18 & 3.56 \\
\hline 700 & 0.813 & 4.400 & 28.39 & 347.81 & 19.30 & 193.71 & 100.13 \\
\hline & & 009 & 0. & 1.29 & 0.24 & 2.08 & 3.58 \\
\hline 750 & 1.485 & 4.414 & 24.18 & 350.83 & 20.04 & 227.49 & 109.30 \\
\hline & & 007 & 0.25 & 0.86 & 0.18 & 2.35 & 2.07 \\
\hline 775 & 1.500 & 4.414 & 21.88 & 350.82 & 20.56 & 251.38 & 117.19 \\
\hline & & 0.007 & 0.23 & 0.83 & 0.18 & 2.59 & 2.09 \\
\hline 800 & 1.424 & 4.407 & 20.23 & 349.37 & 21.64 & 271.88 & 123.55 \\
\hline & & 0.007 & 0.21 & 0.72 & 0.18 & 2.78 & 2.14 \\
\hline 850 & 1.876 & 4.417 & 17.95 & 351.53 & 24.98 & 306.42 & 141.97 \\
\hline & & & & 0.5 & 0.16 & 3.10 & 1.69 \\
\hline 900 & 1.377 & .388 & 14.16 & 345.35 & 32.20 & 388.37 & 178.54 \\
\hline & & & & 0.8 & 0.21 & 4.01 & 2.43 \\
\hline 950 & 0.673 & .316 & 8.57 & 330.5 & 49.16 & 641.70 & 275.34 \\
\hline & & 0.010 & 0.10 & 1.59 & 0.40 & 7.13 & 4.88 \\
\hline 1050 & 0.909 & 4.251 & 2.91 & 317.67 & 122.40 & 1887 & 732 \\
\hline & & & & 1.24 & 0.6 & 20 & \\
\hline 1150 & 1.824 & 4.300 & 1.68 & 327.41 & 167.40 & 3282 & 1033 \\
\hline & & & 0.02 & & & 35 & 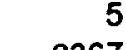 \\
\hline 1200 & 0.559 & 4.317 & 0.73 & 330.83 & 372.52 & 7505 & 2367 \\
\hline & & & 0.01 & & 2.65 & 87 & 18 \\
\hline 1300 & 0.205 & 3.772 & 0.12 & 235.88 & 1839.8 & 44811 & 12168 \\
\hline & & 0.040 & 0.00 & 5.91 & 52.7 & 121 & 348 \\
\hline 1450 & 0.023 & 2.943 & 0.28 & 136.69 & 833.4 & 19617 & 6261 \\
\hline & & 0.134 & 0.03 & & 99.6 & 1891 & 753 \\
\hline 1550 & 0.019 & 2.663 & 28.43 & 112.27 & 38.5 & 193 & 606 \\
\hline & & 0.401 & 8.32 & 32.35 & 16.6 & 57 & 26 \\
\hline
\end{tabular}




\begin{tabular}{|c|c|c|c|c|c|c|c|}
\hline \multicolumn{2}{|c|}{ Colomera Feldspar } & \multicolumn{2}{|c|}{$0.81 \mathrm{mg}$} & \multicolumn{2}{|c|}{$J=0.05403+-0.00020$} & \multirow[b]{2}{*}{87.35} & \multirow[b]{2}{*}{566.12} \\
\hline \multirow[t]{2}{*}{400} & 4.2 & 4.449 & 62.96 & 199.51 & 65.08 & & \\
\hline & & 0.018 & 0.93 & 2.11 & 1.09 & 1.29 & 13.65 \\
\hline \multirow[t]{2}{*}{500} & 6.3 & 3.193 & 5.18 & 90.11 & 14.13 & 1061.96 & 205.14 \\
\hline & & 0.026 & 0.10 & 1.53 & 0.58 & 20.90 & 13.28 \\
\hline \multirow[t]{2}{*}{550} & 14.4 & 3.498 & 15.71 & 110.16 & 3.29 & 350.14 & 20.42 \\
\hline & & 0.014 & 0.20 & 0.90 & 0.21 & 4.52 & 3.43 \\
\hline \multirow[t]{2}{*}{600} & 27.4 & 3.851 & 34.20 & 137.92 & 1.91 & 160.79 & 9.28 \\
\hline & & 0.009 & 0.38 & 0.62 & 0.16 & 1.76 & 1.35 \\
\hline \multirow[t]{2}{*}{625} & 28.3 & 4.020 & 78.13 & 153.32 & 1.84 & 70.40 & 8.41 \\
\hline & & 0.008 & 0.83 & 0.57 & 0.15 & 0.75 & 1.28 \\
\hline \multirow[t]{2}{*}{650} & 35.5 & 4.109 & 324.35 & 161.98 & 1.88 & 16.96 & 7.38 \\
\hline & $+\infty$ & 0.007 & 3.37 & 0.42 & 0.14 & 0.18 & 1.05 \\
\hline \multirow[t]{2}{*}{675} & 95.5 & 4.140 & 384.07 & 165.17 & 2.15 & 14.32 & 8.17 \\
\hline & & 0.006 & 3.88 & 0.21 & 0.13 & 0.14 & 0.54 \\
\hline \multirow[t]{2}{*}{705} & 336.7 & 4.322 & 788.87 & 184.58 & 1.60 & 6.97 & 7.41 \\
\hline & & 0.006 & 7.94 & 0.13 & 0.13 & 0.07 & 0.21 \\
\hline \multirow[t]{2}{*}{725} & 146.5 & 4.386 & 505.30 & 191.94 & 1.71 & 10.88 & 8.00 \\
\hline & & 0.006 & 5.09 & 0.18 & 0.13 & 0.11 & 0.39 \\
\hline 750 & 110.7 & 4.402 & 371.51 & 193.82 & 1.68 & 14.80 & 7.71 \\
\hline & & 0.006 & 3.75 & 0.21 & 0.13 & 0.15 & 1.43 \\
\hline 775 & 149.3 & 4.435 & 607.14 & 197.78 & 1.66 & 9.06 & 8.04 \\
\hline & & 0.006 & 6.12 & 0.15 & 0.13 & 0.09 & 0.38 \\
\hline 800 & 248.0 & 4.454 & 728.91 & 200.10 & 1.66 & 7.55 & 8.27 \\
\hline & & 0.006 & 7.35 & 0.15 & 0.13 & 0.08 & 0.24 \\
\hline 815 & 246.5 & 4.463 & 448.89 & 201.13 & 1.71 & 12.25 & 9.45 \\
\hline & & 0.006 & 4.51 & 0.17 & 0.13 & 0.12 & 0.24 \\
\hline 830 & 247.5 & 4.464 & 670.33 & 201.26 & 1.66 & 8.20 & 8.24 \\
\hline & & 0.006 & 6.75 & 0.16 & 0.13 & 0.08 & 0.84 \\
\hline 850 & 240.6 & 4.464 & 731.54 & 201.25 & 1.65 & 7.52 & 7.85 \\
\hline & & 0.006 & 7.36 & 0.14 & 0.13 & 0.08 & 0.26 \\
\hline 870 & 214.9 & 4.467 & 719.18 & 201.65 & 1.66 & 7.65 & 8.32 \\
\hline & & 0.006 & 7.26 & 0.22 & 0.13 & 0.08 & 0.15 \\
\hline 890 & 188.8 & 4.471 & 633.98 & 202.16 & 1.66 & 8.68 & 8.31 \\
\hline & & 0.006 & 6.39 & 0.16 & 0.13 & 0.09 & 0.31 \\
\hline 915 & 248.5 & 4.478 & 530.95 & 202.96 & 1.67 & 10.36 & 8.05 \\
\hline & & 0.006 & 5.34 & 0.13 & 0.13 & 0.10 & 0.26 \\
\hline 940 & 222.0 & 4.478 & 632.27 & 202.98 & 1.67 & 8.70 & 8.27 \\
\hline & & 0.006 & 6.39 & 0.24 & 0.13 & 0.09 & 0.18 \\
\hline 965 & 162.3 & 4.472 & 475.63 & 202.20 & 1.68 & 11.56 & 8.46 \\
\hline & & 0.006 & 4.79 & 0.18 & 0.13 & 0.12 & 0.19 \\
\hline 1000 & 178.4 & 4.464 & 295.16 & 201.22 & 1.73 & 18.63 & 8.68 \\
\hline & & 0.006 & 2.96 & 0.13 & 0.13 & 0.19 & 0.19 \\
\hline 1050 & 270.0 & 4.467 & 531.96 & 201.61 & 1.68 & 10.34 & 8.19 \\
\hline & & 0.006 & 5.35 & 0.15 & 0.13 & 0.10 & 0.15 \\
\hline 1100 & 364.9 & 4.480 & 610.88 & 203.28 & 1.69 & 9.00 & 8.30 \\
\hline & & 0.006 & 6.13 & 0.11 & 0.13 & 0.09 & 0.10 \\
\hline 1125 & 217.5 & 4.486 & 561.58 & 203.96 & 1.70 & 9.79 & 8.37 \\
\hline & & 0.006 & 5.65 & 0.16 & 0.13 & 0.10 & 0.21 \\
\hline 1150 & 242.3 & 4.497 & 680.63 & 205.34 & 1.70 & 8.08 & 7.95 \\
\hline & & 0.006 & 6.86 & 0.18 & 0.13 & 0.08 & 0.14 \\
\hline 1175 & 174.3 & 4.499 & 669.83 & 205.62 & 1.72 & 8.21 & 8.32 \\
\hline & & 0.006 & 6.76 & 0.20 & 0.13 & 0.08 & 0.17 \\
\hline 1200 & 100.3 & 4.506 & 382.23 & 206.42 & 1.78 & 14.39 & 9.15 \\
\hline & & 0.006 & 3.85 & 0.22 & 0.13 & 0.15 & 0.29 \\
\hline 1250 & 119.7 & 4.509 & 401.56 & 206.79 & 1.74 & 13.70 & 8.56 \\
\hline & & 0.006 & 4.04 & 0.18 & 0.13 & 0.14 & 0.23 \\
\hline 1300 & 55.8 & 4.506 & 241.99 & 206.39 & 1.81 & 22.73 & 9.78 \\
\hline & & 0.006 & 2.44 & 0.17 & 0.13 & 0.23 & 0.45 \\
\hline 1350 & 12.7 & 4.484 & 59.02 & 203.70 & 2.01 & 93.18 & 7.86 \\
\hline & & 0.011 & 0.68 & 1.15 & 0.16 & 1.07 & †.21 \\
\hline 450 & 10.0 & 4.551 & 53.43 & 212.08 & 2.97 & 102.94 & 44.87 \\
\hline
\end{tabular}




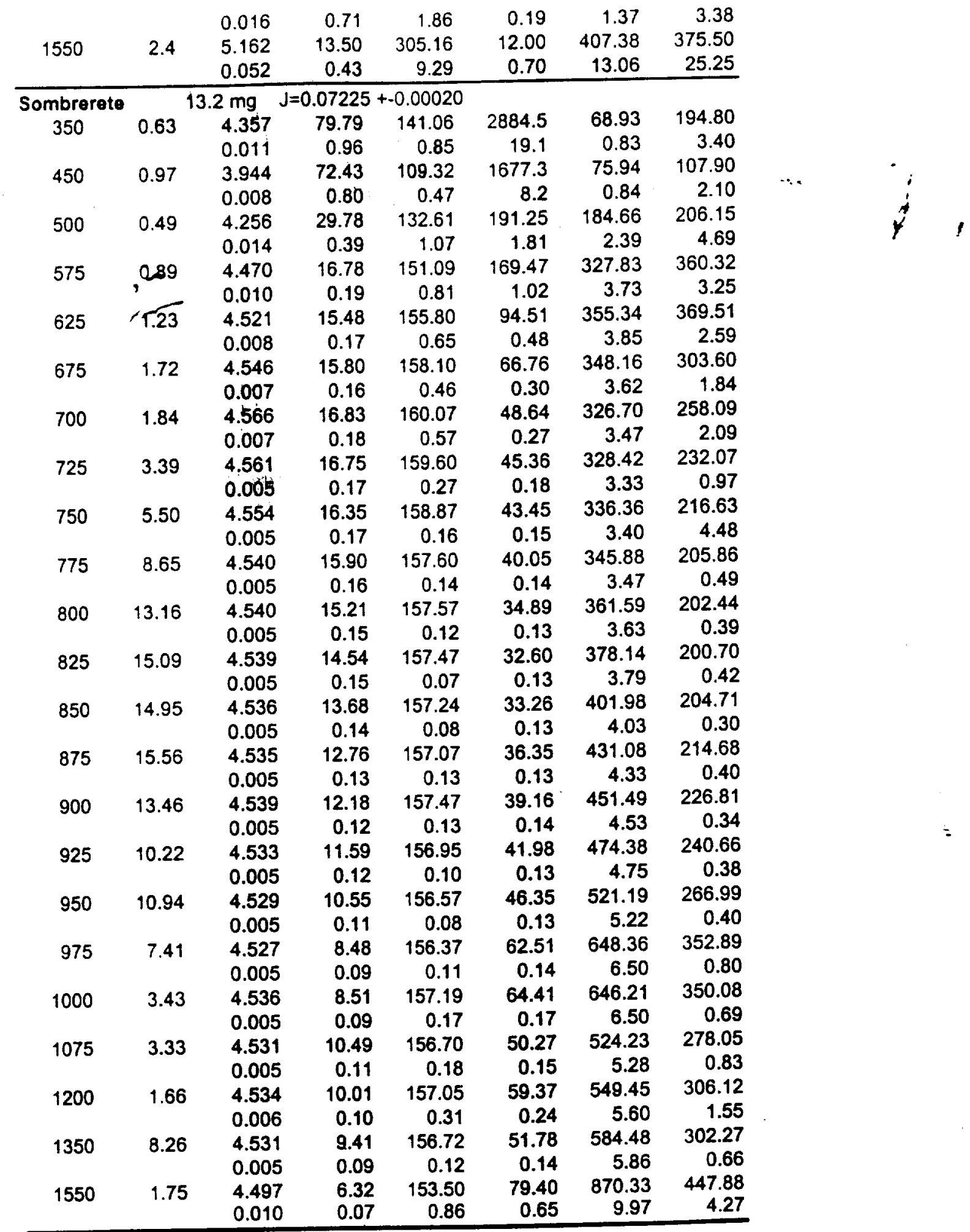

